\title{
Article
}

\section{Fresh State, Rheological and Microstructural Characteristics of Alkali-Activated Mortars Developed Using Novel Dry Mixing Technique under Ambient Conditions}

\author{
Dhruv Sood (D) and Khandaker M. A. Hossain * (D)
}

Citation: Sood, D.; Hossain, K.M.A. Fresh State, Rheological and Microstructural Characteristics of Alkali-Activated Mortars Developed Using Novel Dry Mixing Technique under Ambient Conditions. Appl. Sci. 2021, 11, 8920. https://doi.org/ 10.3390/app11198920

Academic Editor: Fortunato Crea

Received: 26 July 2021

Accepted: 20 September 2021

Published: 24 September 2021

Publisher's Note: MDPI stays neutral with regard to jurisdictional claims in published maps and institutional affiliations.

Copyright: (c) 2021 by the authors. Licensee MDPI, Basel, Switzerland. This article is an open access article distributed under the terms and conditions of the Creative Commons Attribution (CC BY) license (https:// creativecommons.org/licenses/by/ $4.0 /)$.
Department of Civil Engineering, Ryerson University, Toronto, ON M5B 2K3, Canada; dhruv.sood@ryerson.ca

* Correspondence: ahossain@ryerson.ca

\begin{abstract}
Ambient cured alkali-activated mortars (AAMs) are developed through the activation of supplementary cementitious materials (SCMs) by powder form reagents with silica sand using a novel dry-mixing method. The fresh state, rheological, compressive strength and microstructural characteristics of eight AAM mixes are comprehensively investigated. The effects of binary/ternary combinations/proportions of SCMs, different combinations/dosages of powder form reagents and the fundamental chemical ratios $\left(\mathrm{SiO}_{2} / \mathrm{Al}_{2} \mathrm{O}_{3}, \mathrm{Na}_{2} \mathrm{O} / \mathrm{SiO}_{2}, \mathrm{CaO} / \mathrm{SiO}_{2}\right.$ and $\left.\mathrm{Na}_{2} \mathrm{O} / \mathrm{Al}_{2} \mathrm{O}_{3}\right)$ present in the precursors and the reagents are investigated. The AAM mixes obtained compressive strengths ranging from 34 to $42.6 \mathrm{MPa}$ with initial and final setting times between 122 and 458 min and 215 and $483 \mathrm{~min}$, respectively. The yield stress and viscosity of the mixes decreased with the increase in the slump flow spread. All the mixes demonstrated pseudoplastic behavior. The microstructural analysis revealed the formation of more longer polymeric chains comprising $\mathrm{Si}-\mathrm{Al}$ linkages in N-C-A$\mathrm{S}-\mathrm{H} / \mathrm{N}-\mathrm{A}-\mathrm{S}-\mathrm{H}$ gels for reagent one (calcium hydroxide:sodium metasilicate = 1:2.5) mixes, which resulted in a lower slump flow, higher yield stress, higher plastic viscosity and quicker setting times compared to their reagent two (calcium hydroxide: sodium sulfate $=2.5: 1$ ) counterparts.
\end{abstract}

Keywords: alkali activated mortars; supplementary cementitious materials; powder form reagents; rheology; microstructure

\section{Highlights}

- Development of supplementary cementitious materials-based alkali-activated mortars

- Use of powder-based reagents/activators, novel dry mixing techniques and ambient curing

- Evaluation of fresh state, rheological and microstructural characteristics

- Influence of binary/ternary combinations of supplementary cementitious materials and combinations/dosages of reagents

- $\quad$ Relationships between slump flow, yield stress, plastic viscosity and shear rate of mortars

\section{Introduction}

Geopolymers or alkali-activated materials are classified as novel sustainable construction materials developed through geopolymerization or an alkali activation reaction between alkaline activators and aluminosilicate rich source materials, mainly supplementary cementitious materials (SCMs) [1]. These cement-free alkali-activated materials having better fresh state and hardened properties are found to be more sustainable than the currently available green eco-friendly blended cements and concretes in the market incorporating industrial wastes and natural pozzolans such as fly ash, volcanic ash, volcanic pumice and other underused natural materials [1-3]. The alkali-activated materials are generally developed using a conventional two-part wet mixing technique incorporating solution-based reagents. The aluminosilicate-rich materials (precursors) and the alkaline 
solutions (reagents) are first separately prepared and mixed to obtain a wet mix. Various factors associated with this technique limit the commercial application or large-scale production of these materials. The first factor is using highly alkaline solutions and the heat curing of specimens to achieve desired mechanical and durability characteristics comparable to cement-based systems [4-6]. Additionally, preparing large quantities of these corrosive and viscous solutions creates a hostile environment for workers. The requirement of elevated temperature curing is energy-intensive, increases production costs and hinders construction applications $[5,6]$.

In contrast, a one-part geopolymer development technique incorporating s solid/powder form of reagents to improve the reaction process of aluminosilicate-rich materials provides a sustainable solution to the issues associated with the two-part system. These one-part geopolymers developed in ambient curing conditions by adding water to the pre-blended dry mix of precursors and reagents can obtain comparable mechanical and microstructural characteristics to cement-based systems [7,8]. Moreover, the powder form reagents are required in significantly lesser quantities than their counterpart alkaline solutions typically used in the two-part system, which would reduce the production costs of the binders, making them commercially viable [6-8].

Understanding the influence of the ingredients of the alkali activation process on the workability, rheological, thixotropic and strength characteristics are crucial for developing alkali-activated materials from the point of view of their applications in construction industries.

The effect of the SCMs, type and molarity of the alkaline reagents and the aggregate content on the workability and rheological characteristics of alkali-activated slag (AAS) and fly ash (AAFA) mortars in comparison with ordinary Portland cement (OPC) mortars was investigated by Alonso et al. [9]. The slag-based mortars activated with water glass (WG) exhibited lower static yield stress at all the liquid to solid (L/S) ratios than the AASbased mortars with $\mathrm{NaOH}$ due to WG's better fluidizing characteristics. The percentage decrement between the first two static yield stress values for these mortars was consistently between $75-80 \%$. The static yield stress in OPC mortars reduced with the increase in the $\mathrm{L} / \mathrm{S}$ ratios. This was attributed to the reduction in inter-particle frictional forces because of the decrease in solid concentration with the additional water causing a decrement in mortar's resistance to flow. A 74\% reduction in static yield stress was seen in OPC mortars on increasing the L/S ratio from 0.13 to 0.15 . The AAFA-based mortars observed lower values for initial static yield stress than OPC or AAS-based mortars due to the insignificant activation of fly ash. This, in turn, would also nullify the influence of fluidization by WG on the initial yield stress values. The percentage reduction between the first two static yield stress values for both the AAFA mortars was $80 \%$. As a rule, lower values for static yield stress were observed for higher flow spreads, irrespective of the mortar type. A sharp decline in static yield stress values was noted for all the mortars at the specified L/S ratios before entering the plastic state (flow spread ranged between $140 \mathrm{~mm}$ and $190 \mathrm{~mm}$ ) [9].

The slag-based mortars developed by Kwan and Li [10] exhibited a lower flow spread and higher initial torques than OPC and AAFA-based mortars at a specified L/S ratio. OPC mortars exhibited a substantial decrease in torque development initially from 115 to $9.94 \mathrm{~N} . \mathrm{mm}$ when the L/S ratio was increased from 0.13 to 0.20 due to the decrement in inter-particle frictional forces. After the initial decline, the torque remained constant exhibiting thixotropic behavior till the test completion [10]. Another study reported a similar demonstration of thixotropic characteristics by AAS and AAFA-based mortars with slight deviations. Additionally, a reduction in torques was observed with an increase in the water to cement ratio (W/C) for OPC-based mortars. Similarly, at higher L/S ratios, lower values for torques were obtained for AAS and AAFA-based mortars. The addition of sand led to higher torques [11]. A similar observation was made in another study where the amount of liquid needed to obtain a required consistency was increased when a more significant amount of fine aggregates was used, as it led to higher yield stresses [12]. All the mortar mixes (AAS, AAFA and OPC), irrespective of reagents, fitted the Bingham model as per the rheological data [12-14]. However, an investigation by Palacios et al. revealed that 
slag-based mortars activated with WG better fit the Herschel-Bulkley model for rheological characteristics [15]. The other research studies [16,17] also reported that the activation of slag using WG followed the Herschel-Bulkley model for rheological parameters. The slag-based mortars activated using sodium hydroxide $(\mathrm{NaOH})$ [15] or a combination of $\mathrm{NaOH}$ and sodium carbonate $\left(\mathrm{Na}_{2} \mathrm{CO}_{3}\right)$ [18] fitted the Bingham rheological model $[15,18]$. The dynamic yield stress $(\gamma)$ and plastic viscosity $(\eta)$ of the Bingham model were reduced with an increased L/S ratio. This is due to reduced inter-particle frictional forces with decreased solids concentration because of the higher liquid content in the system. The fly ash-based mortars exhibited low plastic viscosity values, while the highest plastic viscosity was observed for OPC and slag-based mortars at the lowest L/S ratios. The slag-based mortars activated with WG demonstrated a higher viscosity value of 2.92 than the slag-mortars activated with $\mathrm{NaOH}$ and OPC mortars $(0.72)$ at an L/S ratio of $0.15[9,15]$.

The influence of water-reducing admixtures (WRAs) on the rheological characteristics of alkali-activated fly ash binders (AAFA) was investigated in another study [19]. The fly ash-based binders were synthesized by mixing fly ash with the alkaline reagent consisting of $12.5 \mathrm{M} \mathrm{NaOH}(85 \%)$ and Water glass (15\%). Lignosulphonates, melamines (first and second generation) and polycarboxylates (latest generation) were used as WRAs. A carboxylatebased superplasticizer was determined to be the most effective based on flowability results. The fly ash-based binders with $0.8 \%$ WRAs exhibited similar flow curves in the ascending branch (when the shear stress increased) and the descending side (the shear stress was decreasing). A similar observation about flow curves was made in another study, reflecting that these alkali-activated mortars or pastes are not influenced by the de-clustering of flocci particles, a typical phenomenon in cement-based binders [20]. The flow curves for fly ash-based binders had a straight lower branch, indicating that these binders comply with the Bingham model. This means that these binders tend to flow when a slight initial force is applied. The binders with WRAs exhibited lower plastic viscosity values than the fly ash mixes without these admixtures. Moreover, the plastic viscosity values of fly ash binders were much larger than the cement-based binders. This can be attributed to the composition of the solution-based reagents. The silicates in the reagents react rapidly with aluminates released from fly ash dissolution forming alkaline aluminosilicate binding gels. These gels formed in the initial phases facilitate the setting and hardening of the pastes. However, the yield stress values for Portland cement binders (without WRAs) were greater than the fly ash systems. This is because the agglomeration of cement particles is taking place in cement pastes. Thus, the de-clustering of flocculated cement grains requires a more significant force, leading to higher yield stresses. A higher flow spread in alkali-activated fly ash systems was not always associated with lower viscosity values as observed for cement-based binders [21]. The slump is influenced by the yield stress and not viscosity determined using theoretical simulations based on the Bingham model [22].

The literature study suggests that there has been no research on the rheological characteristics of alkali-activated mortars (AAMs) incorporating powder form reagents under ambient conditions. Moreover, there is also a lack of a research database on the performance evaluation of AAMs incorporating silica sand as fine aggregates using the one-part drymixing technique. This paper addresses the above-mentioned research gaps by presenting a study on the development and comprehensive evaluation of one-part AAM mixes in terms of fresh state and hardened characteristics. The influence of the ingredients of the mix such as the combinations of reagents (calcium hydroxide, sodium metasilicate and sodium sulfate), binary/ternary combinations and proportions of precursors (fly ash class $\mathrm{C}$, fly ash class $\mathrm{F}$ and ground granulated blast furnace slag) and the fundamental chemical ratios $\left(\mathrm{SiO}_{2} / \mathrm{Al}_{2} \mathrm{O}_{3}, \mathrm{Na}_{2} \mathrm{O} / \mathrm{SiO}_{2}, \mathrm{CaO} / \mathrm{SiO}_{2}\right.$ and $\left.\mathrm{Na}_{2} \mathrm{O} / \mathrm{Al}_{2} \mathrm{O}_{3}\right)$ present in the precursors and the reagents on fresh state, rheological, compressive strength and microstructural characteristics has been investigated to ascertain their suitability for the development of alkali-activated composites (AACs). The findings (fresh state and hardened characteristics) of this research on mortar compositions will certainly facilitate engineers and researchers to further develop high-performing alkali-activated concrete and composites. 


\section{Experimental Program}

The experimental program involved a comprehensive evaluation of geopolymer/alkaliactivated mortars developed from the optimized paste mix compositions (from authors' ongoing research) by incorporating a constant amount ( $30 \%$ by mass of total SCMs) of silica sand $[23,24]$. The performance of the developed mortars had been assessed in terms of fresh state (evolution of slump flow with time and setting times), rheological (yield stress and time dependent plastic viscosity), hardened state (compressive strength and density) and microstructural characteristics through scanning electron microscopy (SEM) coupled with energy-dispersive X-ray spectroscopy (EDS).

\subsection{Materials}

High calcium fly ash class C (FA-C), low calcium fly ash class F (FA-F), ground granulated blast furnace slag (GGBFS), silica sand (maximum particle size, $600 \mu$ ) as well as two types of powder-based reagents were used to develop AAM mixes using the dry mixing technique [24]. Reagent 1 was composed of a combination of calcium hydroxide $\left(\mathrm{Ca}(\mathrm{OH})_{2}\right)$ and sodium meta-silicate $\left(\mathrm{Na}_{2} \mathrm{SiO}_{3} \cdot 5 \mathrm{H}_{2} \mathrm{O}\right)$, having a modular ratio $\left(\mathrm{SiO}_{2} / \mathrm{Na}_{2} \mathrm{O}\right)$ of 1.0. The constituents of the reagent 2 were calcium hydroxide $\left(\mathrm{Ca}(\mathrm{OH})_{2}\right)$ and sodium sulfate $\left(\mathrm{Na}_{2} \mathrm{SO}_{4}\right)$. The specific gravities of calcium hydroxide $(\mathrm{CH})$, sodium metasilicate (SM) and sodium sulfate (SS) were $2.24,1.81$ and $2.70 \mathrm{~g} / \mathrm{cm}^{3}$, respectively. The alkalinity in terms of $\mathrm{pH}$ values of $\mathrm{CH}, \mathrm{SM}$ and SS were 12.4-12.6, 14 and 7, respectively. All the reagents were of lab-grade quality, having a purity of $95-100 \%$. Additionally, Type GU-general use cement was used for producing control mortar mixes. A polycarboxylate ether-based superplasticizer having a $\mathrm{pH}$ of 6 , a specific gravity of $1.06 \mathrm{~g} / \mathrm{cm}^{3}$ and an approximate solid content of $40 \%$ was used as a high range water reducer admixture (HRWRA) to produce flowable mortar mixes. The chemical compositions obtained through X-ray fluorescence spectrometer analysis and the physical properties of SCMs and cement are presented in Table 1. The grain size distribution of the SCMs, cement and silica sand are presented in Figure 1.

Table 1. Chemical composition and physical characteristics of fly ash-class C, fly ash-class F, GGBFS and cement.

\begin{tabular}{ccccc}
\hline Chemical Composition (\%) & FA-C & FA-F & GGBFS & Cement \\
\hline $\mathrm{SiO}_{2}$ & 36.53 & 55.66 & 35.97 & 19.35 \\
$\mathrm{Al}_{2} \mathrm{O}_{3}$ & 18.26 & 22.09 & 9.18 & 5.31 \\
$\mathrm{Fe}_{2} \mathrm{O}_{3}$ & 5.66 & 4.26 & 0.50 & 3.10 \\
$\mathrm{CaO}$ & 20.97 & 7.97 & 38.61 & 62 \\
$\mathrm{MgO}$ & 5.08 & 1.16 & 10.99 & 3 \\
$\mathrm{~K}_{2} \mathrm{O}$ & 0.68 & 1.49 & 0.36 & - \\
$\mathrm{Na}_{2} \mathrm{O}$ & 4.04 & 4.10 & 0.28 & 0.23 \\
$\mathrm{MnO}$ & 0.03 & 0.03 & 0.25 & - \\
$\mathrm{TiO}_{2}$ & 1.26 & 0.61 & 0.39 & - \\
$\mathrm{P}_{2} \mathrm{O}_{5}$ & 0.96 & 0.43 & 0.01 & - \\
$\mathrm{LOI}$ & 2.18 & 1.05 & 0.74 & 2.40 \\
\hline Physical properties & $\mathrm{FA}-\mathrm{C}$ & FA-F & GGBFS & Cement \\
\hline Density $\left(\mathrm{g} / \mathrm{cm}^{3}\right)$ & 2.61 & 2.02 & 2.87 & 3.15 \\
\hline Retained on $45 \mu(\%)$ & $<5$ & $<10$ & $<5$ & $<10$ \\
Blaine fineness $\left(\mathrm{m}^{2} / \mathrm{kg}\right)$ & 315 & 306 & 489.30 & 410 \\
\hline
\end{tabular}




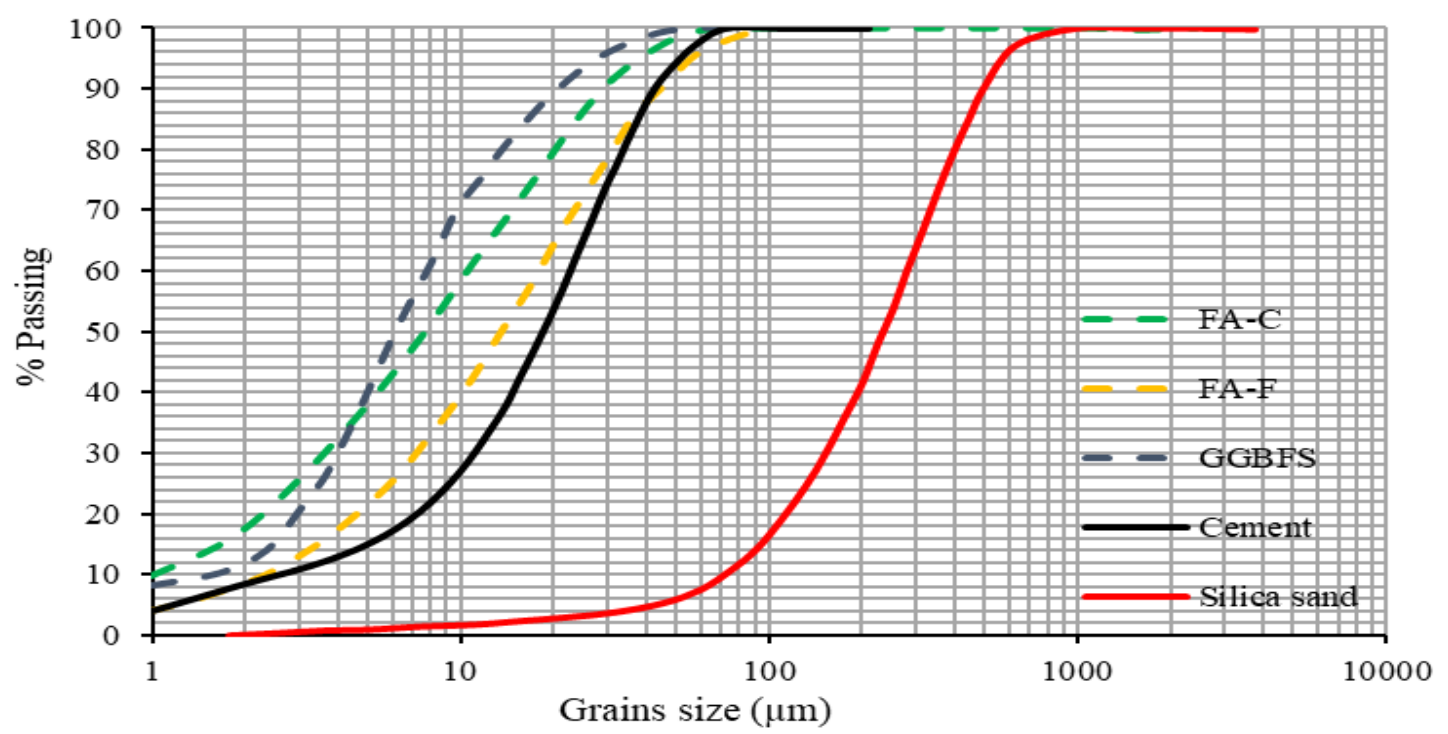

Figure 1. Grain size distribution of SCMs, cement and silica sand.

\subsection{Mix Proportions}

The eight optimized alkali-activated paste binders resulting from four binary/ternary combinations of SCMs, and two powder-based reagents' having two different dosages (from authors' research) were used to develop AAMs with a constant amount of silica sand [23]. The objective was to achieve fresh and rheological characteristics comparable to that of the control mortar $\left(\mathrm{FP}_{\mathrm{C}} \mathrm{M}\right)$ previously established at Ryerson University for producing fiber-reinforced engineered cementitious composites (ECCs) $[25,26]$. The mix proportions for one-part AAMs and control mortar are presented in Table 2 . The total fly ash content varied from 50 to $60 \%$, and the amount of ground granulated blast furnace slag (GGBFS) varied from 40 to $50 \%$ by mass of the total binder content similar to the fly ash and cement content in the control mortar (Table 2). Two dosages/combinations of powder-based reagents were used. A constant amount of silica sand ( 0.3 of total binder content) was added to the binder when it obtained the desired fluidity. One of the objectives was to use these mortars to develop engineered AACs in further studies. Therefore, the quantity of sand (sand to binder ratio of 0.3) was kept similar to fiber reinforced engineered cementitious and geopolymer composites (ranging from 0.3 to 0.36 ) from authors and other existing studies [25-27] to ensure adequate matrix fracture and crack-tip toughness Additionally, use of such low quantity sand will ensure adequate workability for the uniform dispersion of fibers responsible for strain hardening behavior [25-27]. The water to binder ratio varied from 0.35 to 0.375 to achieve a minimum slump flow diameter of $150 \mathrm{~mm}$. The dosage of HRWRA was kept constant as it is acidic and should not act differently for varying mix compositions with alkaline reagents.

The reagent component and the initial chemical ratios in the mix compositions are presented in Table 3. Reagent 1 has a reagent component ratio (calcium hydroxide to sodium metasilicate) of 1:2.5, while reagent 2 has a reagent component ratio (calcium hydroxide to sodium sulfate) of 2.5:1. The performed of these component ratios was superior in terms of compressive strength from authors' research on AABs [23]. The fundamental chemical ratios in terms of silicon oxide to aluminum oxide, sodium oxide to silicon oxide, calcium oxide to silicon oxide and sodium oxide to aluminum oxide were evaluated from the XRF results of the precursors/source materials and the chemical composition of the reagents. These chemical ratios are found to fall within the range of AAMs with adequate workability and strength characteristics as per recent studies on fly ash and slag-based mortars [1]. 
Table 2. Mix proportions for one-part alkali-activated and control mortars.

\begin{tabular}{|c|c|c|c|c|c|c|c|c|c|c|}
\hline Mix-Des. & $\begin{array}{c}\text { Total SCMs } \\
\text { (Binder *) }\end{array}$ & Cement & FA-C & FA-F & GGBFS & $\begin{array}{c}\text { Reagent } \\
\text { Type }\end{array}$ & $\begin{array}{c}\text { Reagent/ } \\
\text { Binder }\end{array}$ & $\begin{array}{l}\text { Silica } \\
\text { Sand }\end{array}$ & $\begin{array}{l}\text { Water/ } \\
\text { Binder }\end{array}$ & HR-WRA ** \\
\hline \multicolumn{11}{|c|}{ Alkali activated mortars (AAMs)—CS: Binary and CFS: Ternary } \\
\hline CSM1 & 1 & 0 & 0.55 & 0 & 0.45 & 1 & 0.09 & 0.3 & 0.35 & 0.02 \\
\hline CSM1N & 1 & 0 & 0.50 & 0 & 0.50 & 1 & 0.09 & 0.3 & 0.35 & 0.02 \\
\hline CFSM1 & 1 & 0 & 0.25 & 0.35 & 0.40 & 1 & 0.09 & 0.3 & 0.35 & 0.02 \\
\hline CFSM1N & 1 & 0 & 0.25 & 0.25 & 0.50 & 1 & 0.09 & 0.3 & 0.35 & 0.02 \\
\hline CSM2 & 1 & 0 & 0.55 & 0 & 0.45 & 2 & 0.12 & 0.3 & 0.375 & 0.02 \\
\hline CSM2N & 1 & 0 & 0.50 & 0 & 0.50 & 2 & 0.12 & 0.3 & 0.375 & 0.02 \\
\hline CFSM2 & 1 & 0 & 0.25 & 0.35 & 0.40 & 2 & 0.12 & 0.3 & 0.375 & 0.02 \\
\hline CFSM2N & 1 & 0 & 0.25 & 0.25 & 0.50 & 2 & 0.12 & 0.3 & 0.375 & 0.02 \\
\hline \multicolumn{11}{|c|}{ Control mortar } \\
\hline $\mathrm{FP}_{\mathrm{C}} \mathrm{M}$ & 1 & 0.45 & 0 & 0.55 & 0 & N.A. & NA. & 0.36 & 0.27 & 0.006 \\
\hline
\end{tabular}

All numbers are mass ratios of the binder. ${ }^{*}$ Binder denotes supplementary cementitious materials $(\mathrm{SCMs})$ and Portland cement $\left(\mathrm{P}_{\mathrm{C}}\right) . \mathrm{C}$ : FA-C, F: FA-F, S: GGBFS, N denotes mixes with equal mass of fly ash (class $\mathrm{C}+$ class F) and GGBFS. Numeric value in the mix designation denotes reagent type. ${ }^{* *}$ HRWRA: Poly-carboxylate ether-based superplasticizer.

Table 3. Reagent component and chemical ratios in mix compositions.

\begin{tabular}{|c|c|c|c|c|c|c|c|c|}
\hline \multirow{2}{*}{$\begin{array}{c}\text { Mix } \\
\text { Designation }\end{array}$} & \multirow{2}{*}{ R. Type } & \multirow{2}{*}{$\begin{array}{c}\text { R. } \\
\text { Component Ratio }\end{array}$} & \multicolumn{4}{|c|}{$\begin{array}{l}\text { Chemical Ratios } \\
\text { (SCMs + Reagents) }\end{array}$} & \multirow{2}{*}{$\begin{array}{l}\text { 28d-Compressive } \\
\text { Strength (MPa) }\end{array}$} & \multirow{2}{*}{$\begin{array}{c}\text { 28d-Density } \\
\left(\mathrm{kg} / \mathrm{m}^{3}\right)\end{array}$} \\
\hline & & & $\mathrm{SiO}_{2} / \mathrm{Al}_{2} \mathrm{O}_{3}$ & $\mathrm{Na}_{2} \mathrm{O} / \mathrm{SiO}_{2}$ & $\mathrm{CaO} / \mathrm{SiO}_{2}$ & $\mathrm{Na}_{2} \mathrm{O} / \mathrm{Al}_{2} \mathrm{O}_{3}$ & & \\
\hline CSM1 & 1 & $1: 2.5$ & 2.62 & 0.09 & 0.84 & 0.23 & 42.6 & 2088 \\
\hline CSM1N & 1 & $1: 2.5$ & 2.71 & 0.08 & 0.87 & 0.23 & 35.0 & 2075 \\
\hline CFSM1 & 1 & $1: 2.5$ & 2.75 & 0.08 & 0.59 & 0.22 & 40.4 & 2030 \\
\hline CFSM1N & 1 & $1: 2.5$ & 2.86 & 0.07 & 0.69 & 0.21 & 34.0 & 2010 \\
\hline CSM2 & 2 & $2.5: 1$ & 2.56 & 0.14 & 1.02 & 0.35 & 41.2 & 2042 \\
\hline CSM2N & 2 & $2.5: 1$ & 2.64 & 0.13 & 1.02 & 0.35 & 35.8 & 2032 \\
\hline CFSM2 & 2 & $2.5: 1$ & 2.69 & 0.12 & 0.73 & 0.32 & 42.0 & 1983 \\
\hline CFSM2N & 2 & $2.5: 1$ & 2.80 & 0.12 & 0.84 & 0.33 & 38.1 & 2055 \\
\hline $\mathrm{FP}_{\mathrm{C}} \mathrm{M}$ & - & - & 2.70 & 0.06 & 0.82 & 0.16 & 43.5 & 1937 \\
\hline
\end{tabular}

All numbers are mass ratios of the binder. Binder denotes supplementary cementitious materials $(\mathrm{SCMs})$ and Portland cement $\left(\mathrm{P}_{\mathrm{C}}\right)$. C: FA-C, F: FA-F, S: GGBFS, N denotes mixes with equal mass of fly ash (class C + class F) and GGBFS. The numerical value in the mix designation denotes reagent type.

\subsection{Mixing, Casting and Curing of Specimens}

The aluminosilicate-rich materials (binder constituents) and the reagents required for each mix composition were weighed per the proportions given in Tables 2 and 3. The reagent components were first mixed thoroughly to form a multi-component reagent/activator. This multi-component reagent was then added to the precursors in the shear mixer. All the ingredients were dry mixed for about $3 \mathrm{~min}$ to obtain a uniform one-part geopolymer binder mixture. Then, two-thirds of the required water was gradually added to the mix, similarly to the development of cement-based binders. The HRWRA mixed with the remaining water was gradually added to make the paste flowable for incorporating silica sand as per the proportions given in Table 2. The incorporation of sand was followed once the paste became flowable so that the sand did not hinder the initial alkali activation reactions. After sand addition, the remaining HRWRA mixed with water was added gradually to the mortar. The total mixing procedure lasted about $12-15 \mathrm{~min}$. At least 12 cube specimens having dimensions of $50 \mathrm{~mm} \times 50 \mathrm{~mm} \times 50 \mathrm{~mm}$ were prepared for each mix composition for compressive strength testing. All the specimens were kept in the curing room/chamber maintained at a temperature of $23 \pm 3{ }^{\circ} \mathrm{C}$ and $95 \pm 5 \%$ relative humidity (RH). The molds were demolded $24 \mathrm{~h}$ after casting and were kept in the curing chamber until the days of testing. 
The above dry-mixing method avoided the handling of solution-based corrosive alkaline reagents. Additionally, it used powder form reagents in lesser quantities (0.09-0.12 of total binder content) than the conventional solution-based reagents $(0.35$ of total binder content) used in previous research works $[23,24,28]$. Thus, this method demonstrated the enhanced sustainability, user-friendliness and commercial viability to develop AAMs on a large scale compared to the conventional two-part method.

\subsection{Test Methods}

The rheological characteristics of the AAM mixes in terms of yield stress, timedependent plastic viscosity and hysteretic plastic viscosity response were studied using the DV3TRV rheometer by Brookfield. The yield test was conducted using a vane spindle (V-73) rotating at a speed of 3.5 RPM as it can be easily immersed without disturbing the underlying sample. A rheological procedure was defined separately to generate a hysteresis loop for the viscosity of the AAM mixes. The hysteresis loop behavior program consisted of two phases for the shear rate in revolutions per minute (RPM): ramp-up and ramp-down, as indicated in Figure 2. The shear rate was gradually increased from 0.5 to 3.5 RPM, and then it was steadily decreased from 3.5 to 0.5 RPM in the ramp-down stage. Each RPM was administered for $60 \mathrm{~s}$.

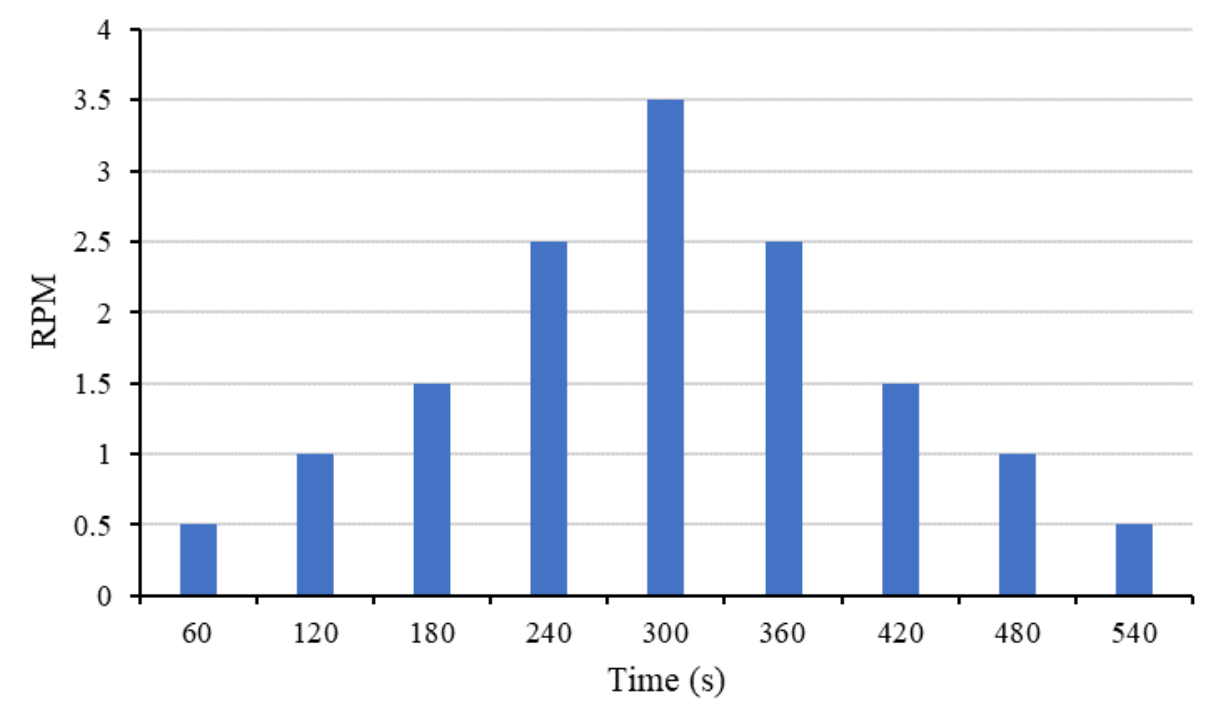

Figure 2. Shear rate (RPM) steps for hysteresis loop behavior of mixes.

On the other hand, the time-dependent behavior of plastic viscosity was assessed using a stepped viscosity program in which viscosity measurements were made for 5-min duration with a spindle rotational speed of $3.5 \mathrm{RPM}$ at 0,30 and 60 min post mixing. A vane spindle (V-73) was administered for both the rheological programs to compare the behavior with the yield of the materials. Additionally, the slump flow measurements were made using a mini-slump cone at the same time intervals $(0,30$ and 60 min post mixing) in compliance with ASTM C1437 [29]. The relative slump (T) was evaluated from the slump flow spread diameters based on the following equation (1) [28]:

$$
T=\left[\left(\frac{d}{d_{0}}\right)^{2}\right]-1
$$

where $d=$ average of two measured diameters of the matrix spread and $d_{0}=$ bottom diameter of the conical cone $(100 \mathrm{~mm})$. The initial and final setting times of the mortar mixes were determined as per ASTM C 191-a [30]. The compressive strength test at 28 days was conducted on $50 \mathrm{~mm} \times 50 \mathrm{~mm} \times 50 \mathrm{~mm}$ cube specimens according to ASTM C109/C109M-2016 [31]. 
The SEM micrographs coupled with EDS analysis were performed on the alkaliactivated and control mortars to determine the reaction products. The specimens were taken from the core of the failed compression test cubes at 28 days for SEM/EDS analysis. The specimens were grounded and softly polished with sandpaper down to $30 \mu \mathrm{m}$. A gold coating was added to the specimens to make the surface conductive. The fracture surface was studied using the secondary electrons (SE) and the backscattered electron (BES) at $20 \mathrm{kV}$. The specimens' morphology was studied at $100 \times(100 \mu \mathrm{m})$, and the reaction products assessment was performed at $2000 \times(10 \mu \mathrm{m})$.

\section{Results and Discussions}

Table 3 summarizes the 28-day compressive strength and density of the alkali-activated and control (cement-based) mortars. All the AAMs achieved satisfactory 28-day compressive strengths ranging from 34 to $42.6 \mathrm{MPa}$ ( $>18 \mathrm{MPa}$ specified for structural concrete as per ACI 318 [32]), which is comparable to $43.5 \mathrm{MPa}$ (control cement-based mortar) and other conventional two-part FA and GGBFS based geopolymers from existing studies $[23,24,28]$ (Table 3). The binary (FA-C + GGBFS designated as CS) mortars having higher $\mathrm{CaO} / \mathrm{SiO}_{2}$ ratios (as presented in Table 3 ) obtained higher compressive strengths (than their ternary (FA-C + FA-F + GGBFS designated as CFS) counterparts due to the formation of additional CSH binding phases/gels with C-A-S-H/N-C-A-S-H causing further densification of the matrix, as evident from the microstructural analysis (discussed later) and higher density (2032-2088 kg/m ${ }^{3}$ compared to $1983-2055 \mathrm{~kg} / \mathrm{m}^{3}$ of their ternary counterparts) as presented in Table 3. The following subsections present the fresh state, rheological and microstructural characteristics of the alkali-activated and control (cement-based) mortars.

\subsection{Fresh State and Rheological Characteristics}

The fresh state and rheological characteristics of the cement and alkali-activated mortars in terms of mini-slump flow spread with the corresponding relative slump and viscosity at 0,30 and $60 \mathrm{~min}$ of mixing, yield stress immediately after mixing; the shear modulus and setting times are presented in Table 4.

Table 4. Fresh state and rheological characteristics of alkali-activated and cement mortars.

\begin{tabular}{|c|c|c|c|c|c|c|c|c|c|c|c|c|c|}
\hline \multirow{2}{*}{ Mix-ID } & \multicolumn{3}{|c|}{$\begin{array}{c}\text { Slump Flow }(\mathrm{mm}) \text { with } \\
\text { Time }(\mathrm{min})\end{array}$} & \multicolumn{3}{|c|}{$\begin{array}{c}\text { Relative Slump (T) with } \\
\text { Time (min) }\end{array}$} & \multicolumn{3}{|c|}{$\begin{array}{l}\text { Viscosity (Pa.s) with Time } \\
\text { (min) }\end{array}$} & \multirow{2}{*}{$\begin{array}{l}\text { Yield Stress } \\
\text { (Pa) }\end{array}$} & \multirow{2}{*}{$\begin{array}{c}\text { Shear } \\
\text { Modulus } \\
\text { (Pa/rad) }\end{array}$} & \multicolumn{2}{|c|}{ Setting Time (min.) } \\
\hline & 0 & 30 & 60 & 0 & 30 & 60 & 0 & 30 & 60 & & & Initial & Final \\
\hline FPcM & 480 & 500 & 490 & 22.0 & 24.0 & 23.0 & 1.8 & - & - & 6.6 & 9.5 & 474 & 522 \\
\hline CSM1 & 200 & 105 & 100 & 3.0 & 0.1 & 0.0 & 64.7 & 92.2 & 120.1 & 160.8 & 300.1 & 216 & 248 \\
\hline CSM1N & 150 & 105 & 100 & 1.2 & 0.1 & 0.0 & 99.8 & 123.1 & 133.0 & 129.8 & 373.4 & 225 & 250 \\
\hline CSM2 & 250 & 180 & 130 & 5.2 & 2.2 & 0.7 & 30.2 & 32.7 & 34.8 & 62.2 & 129.4 & 311 & 369 \\
\hline CSM2N & 230 & 170 & 140 & 4.3 & 1.9 & 1.0 & 48.3 & 56.0 & 69.1 & 102.6 & 383.9 & 277 & 345 \\
\hline CFSM1 & 245 & 105 & 100 & 5.0 & 0.1 & 0.0 & 36.7 & 151.3 & 120.6 & 77.4 & 250.9 & 145 & 230 \\
\hline CFSM1N & 235 & 100 & 100 & 4.5 & 0.0 & 0.0 & 73.2 & 149.8 & - & 65.4 & 163.9 & 122 & 215 \\
\hline CFSM2 & 300 & 290 & 170 & 8.0 & 7.4 & 1.9 & 12.7 & 26.9 & 22.0 & 54.4 & 128.0 & 458 & 483 \\
\hline CFSM2N & 290 & 300 & 175 & 7.4 & 8.0 & 2.1 & 18.6 & 30.7 & 33.0 & 51.2 & 123.0 & 438 & 472 \\
\hline
\end{tabular}

\subsubsection{Slump Flow, Viscosity and Setting Times}

The slump flow and viscosity were measured simultaneously at the same specified time intervals $(0,30$ and $60 \mathrm{~min})$ of post mixing to observe their relationship to time. The slump flow diameter measurements at a specified time were normalized by dividing the flow diameter at a specified time ' $t$ ' $\left(D_{T}\right)$ by the initial slump flow diameter $\left(D_{0}\right)$ at 0 min of post mixing $\left(t_{0}\right)$ to determine the normalized slump flow spread $\left(D_{N}\right)$. Additionally, the same kind of normalization was adopted for viscosity values to observe the relative viscosity $\left(\mu_{\mathrm{N}}\right)$ with time. This normalization allowed making the relative comparison of slump flow and viscosity of different AAMs. 
The slump flow spread, relative slump and viscosity of AAM mixes varied from 150 to $300 \mathrm{~mm}, 1.2$ to 8.0 and 12.7 to $99.8 \mathrm{~Pa}$.s, respectively, at 0 min post-mixing (Table 4 ). The initial setting times of the AAM mixes varied from 122 to $458 \mathrm{~min}$, while the final setting times ranged between 215 and $483 \mathrm{~min}$ (Table 4). The viscosity of the mix compositions was observed to be related to the slump flow diameter values. In general, the slump flow diameter and relative slump gradually reduced as time progressed, resulting in higher viscosity values at $60 \mathrm{~min}$ of post-mixing. The variation of slump flow spread showing a reduction (from $290 \mathrm{~mm}$ to $175 \mathrm{~mm}$ ) with time for a typical ternary mix CFSM2N is illustrated in Figure 3.

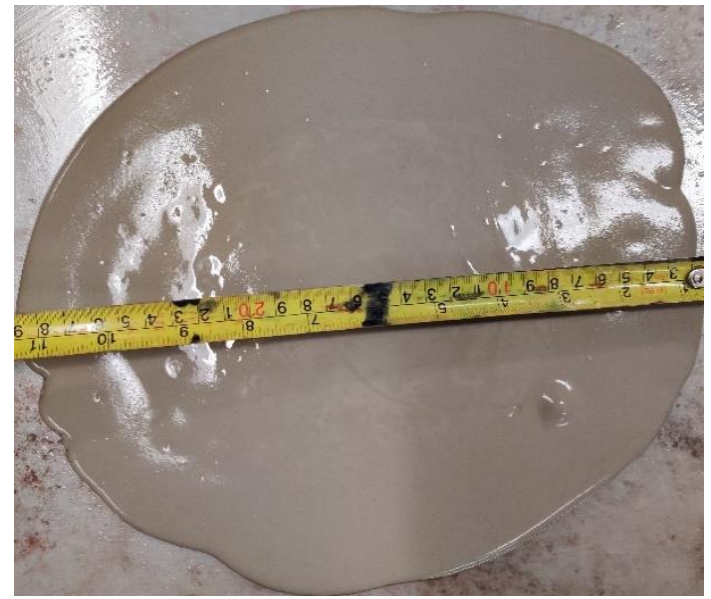

(a)

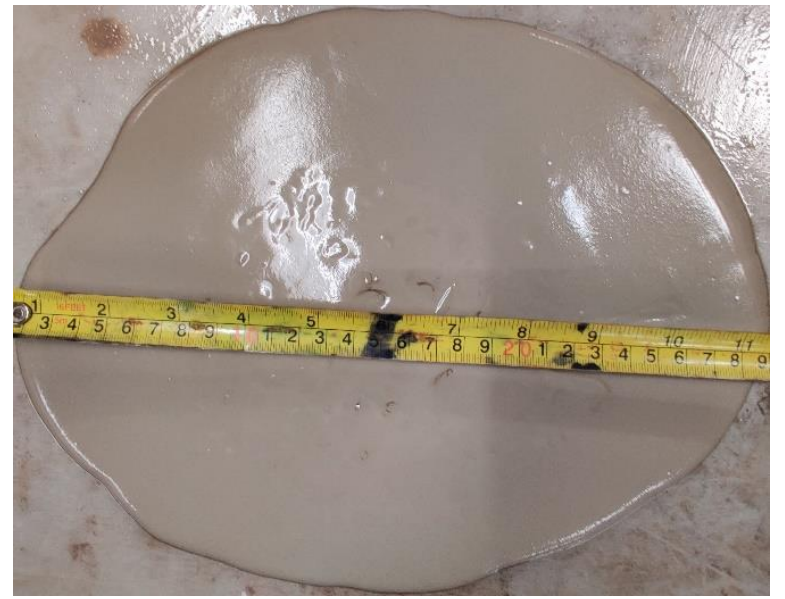

(b)

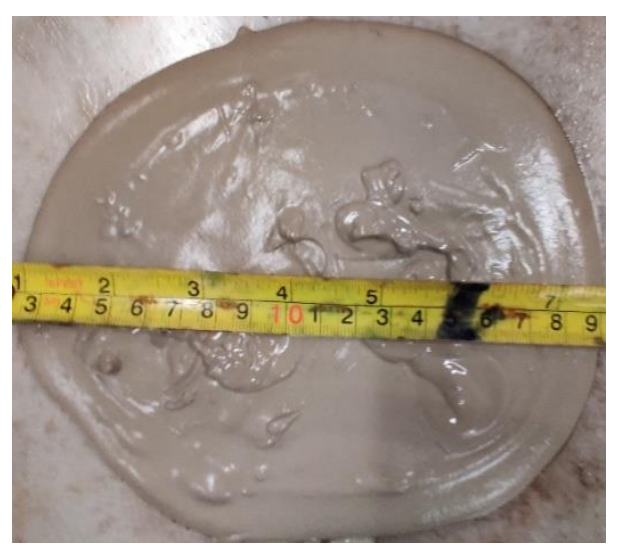

(c)

Figure 3. Variation of slump flow spread for CFSM2N at (a) $0 \mathrm{~min}$; (b) $30 \mathrm{~min}$; (c) $60 \mathrm{~min}$.

The evolution of normalized viscosity $\left(\mu_{N}\right)$ and relative slump flow spread $\left(D_{N}\right)$ with time $(0,30$ and $60 \mathrm{~min})$ is presented in Figure $4 a, b$. It can be noted from Figure $4 a, b$ that the normalized viscosity increased, and normalized slump flow decreased with the increase in time. The rate of increase or decrease was higher for ternary (CFS) mixes than their binary (CS) counterparts. 


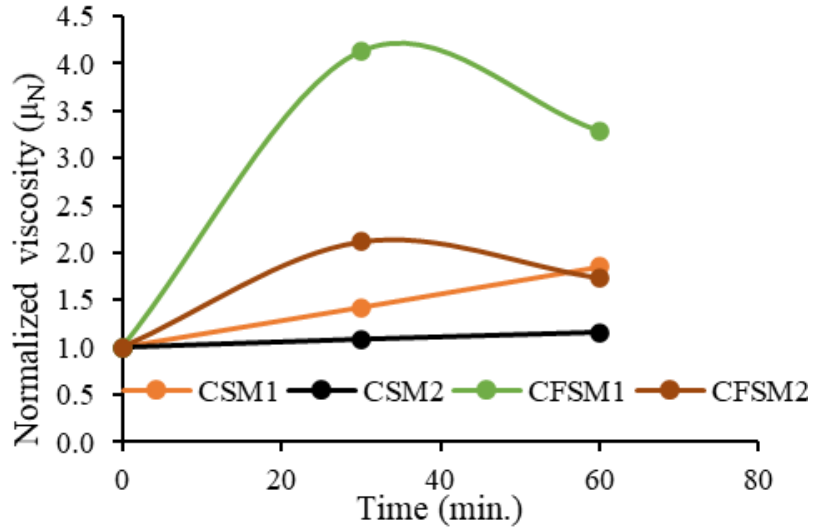

(a)

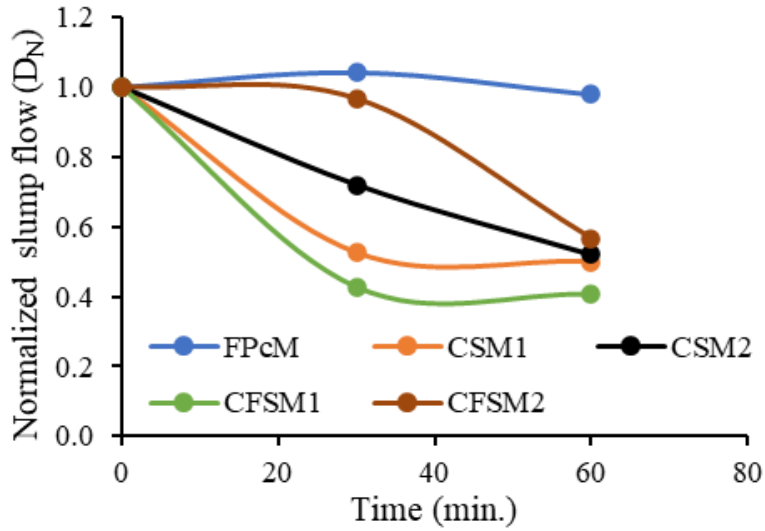

(b)

Figure 4. (a) Normalized viscosity with time; (b) Normalized slump flow spread with time.

A linear correlation was observed between the slump flow spread and viscosity at different times of 0,30 and $60 \mathrm{~min}$ (as noted in Figure 5) with good correlation coefficients of $0.87,0.71$ and 0.83 , respectively. The viscosity of the mixes increased with the decrease in the slump flow at all time intervals, as represented by the equations noted in Figure 5. These correlation equations reveal that the elapsed time did not change the linear relation between viscosity and slump flow; however, the rate of decrease as indicated by the slope of the graphs decreased with respect to time.

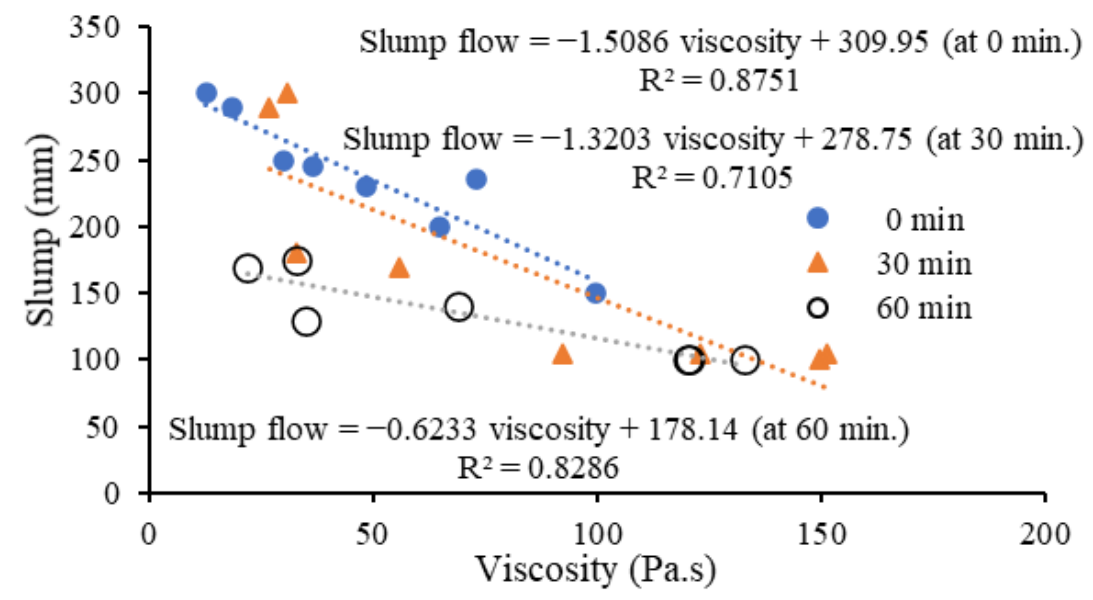

Figure 5. Viscosity versus slump flow.

The control cement-based mortar $\left(\mathrm{FP}_{\mathrm{C}} \mathrm{M}\right)$ produced the highest slump flow spread/ relative slump of $480 \mathrm{~mm} / 22.0$ and the lowest viscosity of 1.8 Pa.s at 0 min after mixing. This control mix exhibited the highest initial (474 min) and final (522 min) setting times. Almost no change in slump flow spread/relative slump nor viscosity was observed with time in the control mortar produced with a high volume of fly ash (FA). The plastic viscosity values of all the AAM mixes were found to be higher than $\mathrm{FP}_{\mathrm{C}} \mathrm{M}$.

The type of reagents influenced the slump flow, viscosity and setting times of AAM mixes. The mixes with reagent one having a higher $\mathrm{SiO}_{2} / \mathrm{Al}_{2} \mathrm{O}_{3}$ ratio (as noted in Table 3) exhibited higher viscosity with a lower slump flow/relative slump and lower setting times than their counterparts incorporating reagent two and the control cement-based mortar. This can be attributed to the higher alkalinity of the sodium metasilicate and silicate content present in reagent one, which facilitated the faster dissolution of aluminum and silicate ions from the SCMs, leading to the quicker formation of reaction products. A similar observation was reported in an earlier study where the silicates present in the alkaline solutions reacted rapidly with aluminates released from fly ash dissolution forming alkaline 
aluminosilicate binding gels. These gels formed in the initial phases facilitate the pastes' setting and hardening, leading to higher viscosities and lower slump flow spread with time $[19,33]$. Lower reductions in slump flow spread at 30 and $60 \mathrm{~min}$ of post-mixing were also evident for mortars with reagent two, as shown in Figure $4 \mathrm{~b}$. A reduction in the slump flow / relative slump from 250 to $180 \mathrm{~mm}$ (up to a $28 \%$ reduction)) $/ 5.2$ to 2.2 for mortars with reagent two was observed compared to the reduction from 245 to $105 \mathrm{~mm}$ (up to $57 \%$ reduction) $/ 5.0$ to 0.1 for mortars with reagent one at $30 \mathrm{~min}$ (Table 4). For instance, the mortar mixed with reagent one, mix CFSM1, almost lost its entire workability at $30 \mathrm{~min}$, exhibiting a decrease in slump flow spread/relative slump flow spread from $245 \mathrm{~mm} / 5.0$ at $0 \mathrm{~min}$ to $105.0 \mathrm{~mm} / 0.1$.

The water content and liquid to solid (L/S) ratio are also essential factors in producing mixes with higher slump flow and lower viscosity, as indicated in Figure 5. The presence of a higher water content and higher L/S ratios resulted in higher slump flow spread diameters/relative slump, higher setting times and lower viscosity values for mixes with reagent two compared to their reagent one counterparts, as can be seen from Tables 2 and 3 . Similar behavior was observed in previous studies on the two-part alkali-activated fly ash and slag mortars with the increase in L/S ratios $[9,34]$. This was attributed to the decreased interparticle frictional forces and increased particle spacing/thickness of the fluid film from the higher amount of suspended fluid in the suspension, which eventually led to a decrease in yield stress and plastic viscosity. Moreover, an increased water content also reduced the concentration of the alkali ions in the solution. This reduction in the alkali ion concentration resulted in an activation solution with lower viscosity, reducing yield stress and plastic viscosity values. An increase in viscosity was observed with the reduction in slump flow spread/relative slump over time. An increase in viscosity of up to $112 \%$ (12.7 to 26.9 Pa.s) and $312 \%$ (36.7 to 151.3 Pa.s) was noted for mortars with reagent two and reagent one, respectively, at $30 \mathrm{~min}$ post mixing, as presented in Table 4.

\subsubsection{Hysteretic Viscosity Behavior of Mortars}

Table 5 presents the shear rate (in RPM and 1/s) and the corresponding viscosity of different mix compositions with the increase followed by the decrease in RPM. The mortar $\left(\mathrm{FP}_{\mathrm{C}} \mathrm{M}, \mathrm{CSM} 2, \mathrm{CSM} 2 \mathrm{~N}, \mathrm{CFSM} 2\right.$ and CFSM2N) mixes regained their initial viscosity at 0.5 RPM exhibiting hysteretic loop characteristics (Table 5).

Table 5. Hysteresis loop behavior of viscosity for mortars.

\begin{tabular}{|c|c|c|c|c|c|c|c|c|c|c|}
\hline \multirow{2}{*}{ Speed } & \multirow{2}{*}{$\begin{array}{l}\text { Shear Rate } \\
\text { (RPM/60) }\end{array}$} & \multicolumn{9}{|c|}{ Mix-ID } \\
\hline & & FPcM & CSM1 & CSM1N & CSM2 & CSM2N & CFSM1 & CFSM1N & CFSM2 & CFSM2N \\
\hline (RPM) & $(1 / s)$ & \multicolumn{9}{|c|}{ Viscosity (Pa.s) } \\
\hline 0.5 & 0.01 & 12.8 & 311.4 & 332.8 & 280.3 & 234.3 & 195.8 & 571.4 & 93.1 & 67.4 \\
\hline 1 & 0.02 & 8.0 & 173.9 & 156.8 & 142.8 & 122.5 & 114.5 & 344.0 & 48.2 & 36.4 \\
\hline 1.5 & 0.03 & 5.7 & 122.7 & 125.2 & 95.9 & 84.9 & 83.1 & 235.0 & 33.5 & 25.3 \\
\hline 2.5 & 0.04 & 4.1 & 73.8 & 90.7 & 58.0 & 53.5 & 51.6 & 130.3 & 21.8 & 16.9 \\
\hline 3.5 & 0.06 & 3.2 & 52.1 & 66.0 & 41.3 & 39.6 & 37.1 & 86.4 & 16.7 & 13.2 \\
\hline 2.5 & 0.04 & 3.4 & 76.8 & 100.8 & 53.9 & 52.6 & 54.8 & 120.3 & 22.3 & 18.0 \\
\hline 1.5 & 0.03 & 5.0 & 139.5 & 184.8 & 83.8 & 84.2 & 98.8 & 211.1 & 35.0 & 28.5 \\
\hline 1 & 0.02 & 7.0 & 229.5 & 305.0 & 120.4 & 123.6 & 161.6 & 329.0 & 51.4 & 42.8 \\
\hline 0.5 & 0.01 & 12.8 & 513.6 & 676.2 & 227.9 & 240.8 & 368.1 & 701.9 & 99.5 & 85.6 \\
\hline
\end{tabular}

The reduction in viscosity with an increase in shear rate (0.5 to $3.5 \mathrm{RPM})$ represented by a solid line (shear ramp-up) and the gain in viscosity with the decrease in shear rate ( 3.5 to 0.5 RPM) indicated by the dotted line (shear ramp-down) are presented in Figure 6a,b. The viscosity with shear rate plots indicates a rapid decrease in viscosity for all the mixes 
with a more rapid decrease for mixes with reagent one till 0.02/s (1 RPM). This can be attributed to the higher degree dissolution potential of sodium metasilicate, which led to the faster release of water during the initial periods of the alkali activation process. All the mortar mixes showed decreased viscosity with an increase in shear rate up to 3.5 RPM depicting pseudoplastic behavior. The viscosity of different mix compositions followed the same path backward initially when the RPM started to reduce from 3.5 to 0.5 RPM, obtaining equal or higher final viscosities in all the mortar mixes at 0.5 RPM with few (lower final viscosity for mortar mix CSM2) exceptions. A similar trend was noted in a previous study where the two-part fly ash-based binders exhibited similar flow curves in both directions (shear ramp up and ramp down) [19]. This reflects that these alkali-activated pastes or mortars are not influenced by the de-clustering of flocci, which is a typical phenomenon in cement-based materials [19].

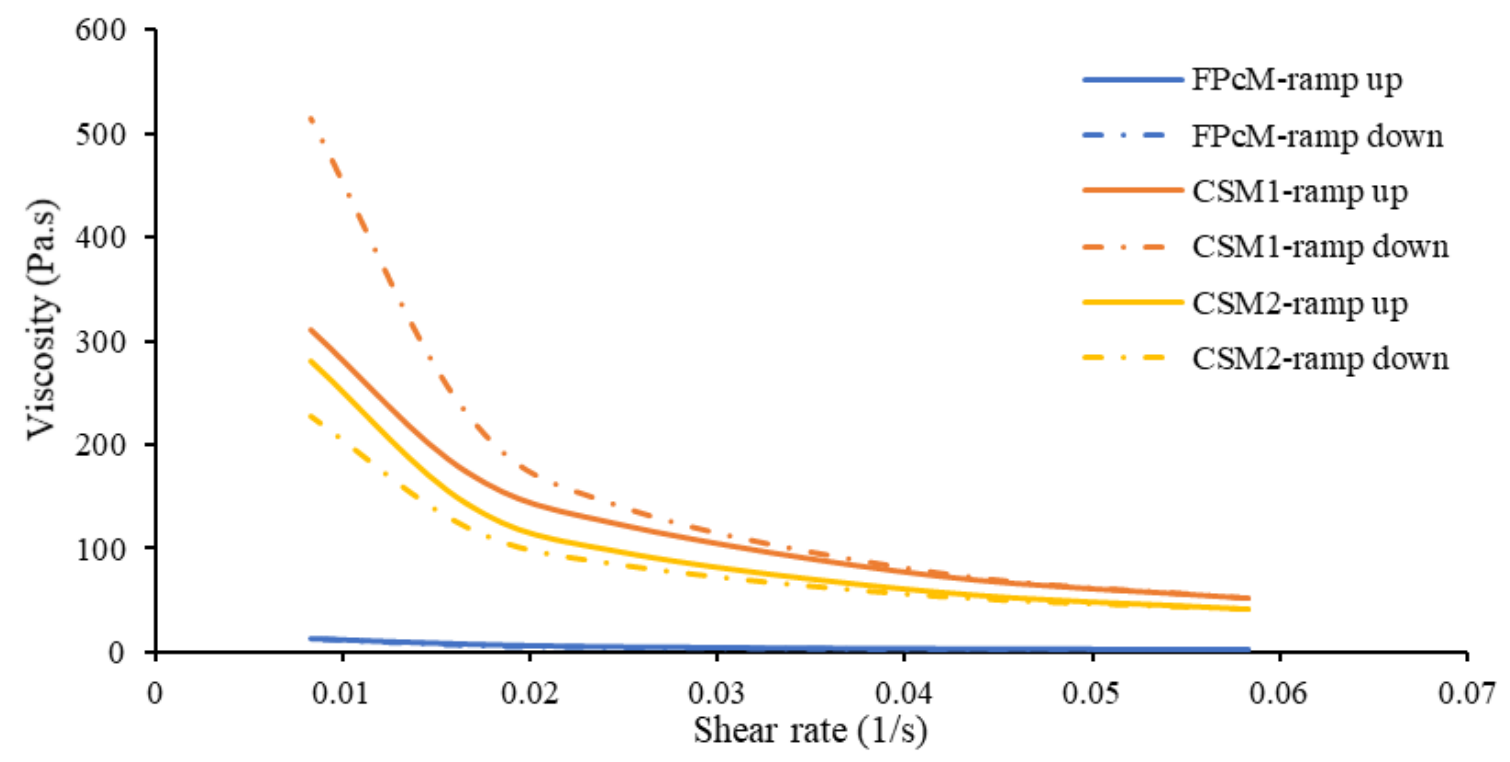

(a)

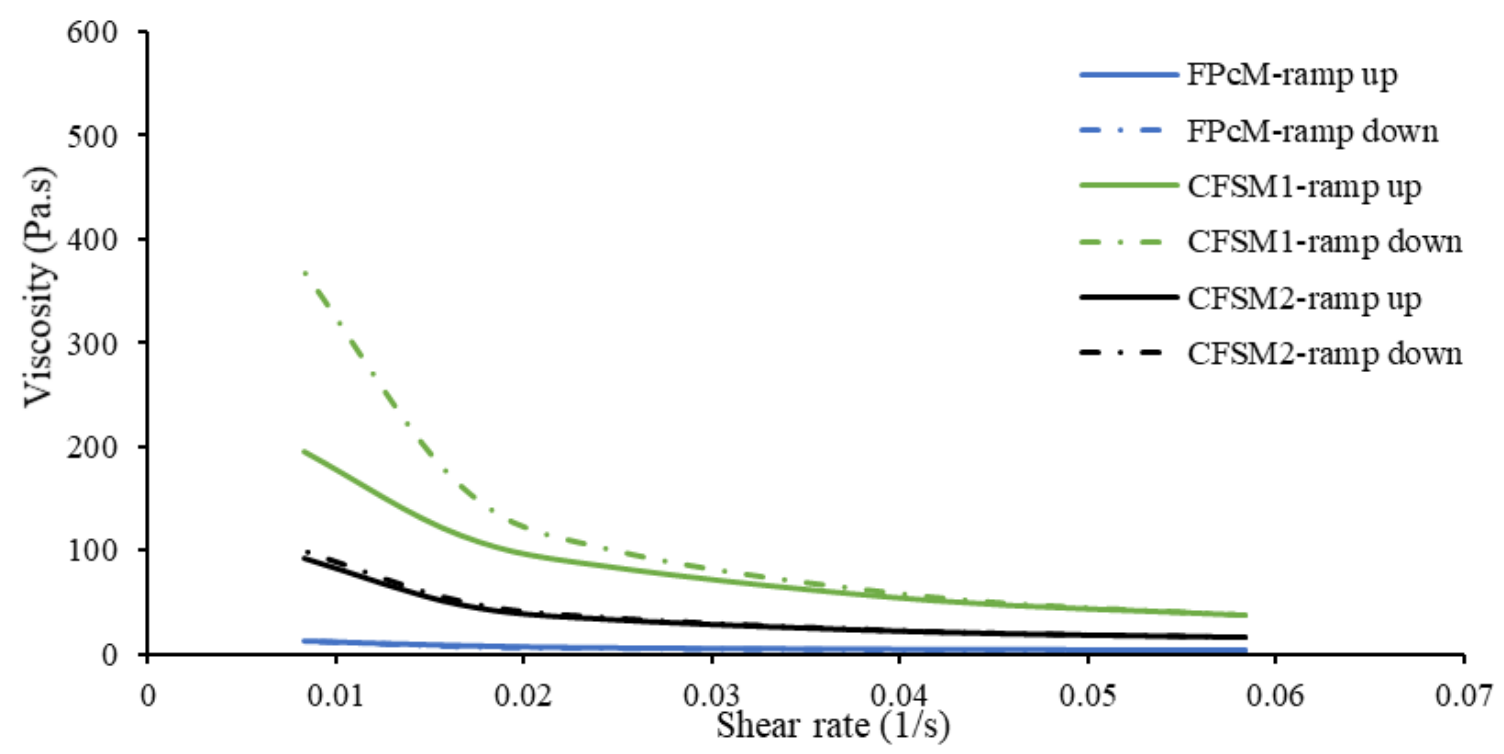

(b)

Figure 6. (a): Viscosity versus the shear rate of binary mortars; (b): Viscosity versus the shear rate of ternary mortars. 
The control mortar mix (FPcM) obtained the same final viscosity of 12.8 Pa.s at 0.5 RPM, as indicated in Table 5. A lower final value of viscosity was observed for AAM mix CSM2. Almost similar final and initial viscosity values were observed for the mixes CSM2N and CFSM2. These mixes with reagent two exhibited a higher slump flow, lower viscosity and yield stresses than those with reagent one. This can be attributed to the dominant formation of cementitious reaction products (C-A-S-H/C-S-H) in mixes with reagent two (CSM2, CSM2N, CFSM2 and CFSM2N) having shorter chains than the Si-Al linkages in NA-S-H/N-C-A-S-H gels being formed predominantly in the mortar mixes with reagent one (CSM1, CSM1N, CFSM1 and CFSM1N). All the mortar mixes with reagent one obtained higher final viscosity values at 0.5 RPM due to their faster reaction process owing to the system's high alkalinity. A similar observation was made in an earlier investigation on two-part fly ash-based geopolymer paste where sodium $(\mathrm{Na})$ based activators resulted in considerably higher viscosities than potassium (K)-based activators with both a hydroxide and silicate-based solution [35]. Additionally, greater viscosity values were obtained for Na-based activators than their K-based counterparts due to the lower molecular weight of sodium. Consequently, more sodium silicate was needed than potassium silicate to achieve similar silica modulus and other ratios $\left(\mathrm{Na}_{2} \mathrm{O} / \mathrm{FA}\right.$ and $\left.\mathrm{K}_{2} \mathrm{O} / \mathrm{FA}\right)$. Higher values of these ratios mean an increase in the ionic concentrations of $\mathrm{Na}$ or $\mathrm{K}$ and $\mathrm{Si}$ in the solution. Such higher concentrations of alkali activators result in increased ion-dipole forces and a higher quantity of Si-O-H-Na/K within the solutions leading to higher viscosity values [35].

\subsubsection{Yield Stress of Mortars}

Figure 7a,b present the shear stress-strain relationship for binary and ternary mortar mixes. The starting point of the flat portion of the curve indicating no change in shear stress represents the material's yield stress. The yield stress for binary and ternary mortars varied from 62 to $161 \mathrm{~Pa}$ and 51 to $77 \mathrm{~Pa}$, respectively. The control mortar $\left(\mathrm{FP}_{\mathrm{C}} \mathrm{M}\right)$ obtained the lowest yield stress of 6.6 Pa due to the formation of shorter C-S-H linkages compared to long chains of geopolymerization/alkali activation consisting of $\mathrm{Si}-\mathrm{Al}$ with shared oxygen atoms. The shear modulus is the ratio of shear stress to shear strain for pure shear within the elastic/proportional limit. The mortars with reagent one (CSM1, CSM1N, CFSM1 and CFSM1N) exhibited higher shear modulus (164 to $373 \mathrm{~Pa} / \mathrm{rad}$ ), resulting in more significant yield stresses in comparison to the mixes with reagent two (CSM2, CSM2N, CFSM2 and CFSM2N) and the control mix $\left(\mathrm{FP}_{\mathrm{C}} \mathrm{M}\right)$ presented in Table 4 . This can be attributed to the higher ' $\mathrm{SiO}_{2} / \mathrm{Al}_{2} \mathrm{O}_{3}$ ' ratio in the mixes incorporating reagent one, leading to comparatively more and the faster formation of Si-Al linkages and colloidal Si-O-H-Na complexes due to the high alkalinity $(\mathrm{pH}=14)$ of sodium metasilicate. A similar formation of such aggregate complexes of few nanometers in dimension was seen in previous studies utilizing alkaline silicate solution-based reagents [33,36]. Additionally, the higher L/S ratio in mixes with reagent two compared to their counterparts with reagent one reduced the interparticle frictional forces and resulted in lower yield stresses. This behavior is consistent with the observations reported in a previous study where the yield stress of fly ash-Na/K-silicate suspensions was found to be influenced by interparticle forces [35]. However, the mix 'CSM2N' had the highest shear modulus owing to the comparatively 5\% higher GGBFS content than its CSM2 counterparts. This is because the characteristic angular particle shape and high Blaine fineness of GGBFS provided a higher surface area for alkali activation and quicker reaction products comprising both C-S-H and C-A-S-H. This led to the faster densification of the reaction products resulting in higher yield stresses. 


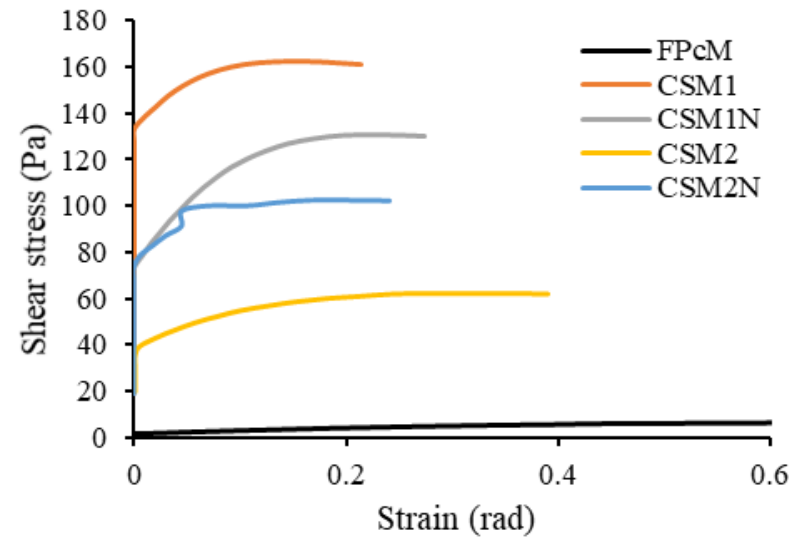

(a)

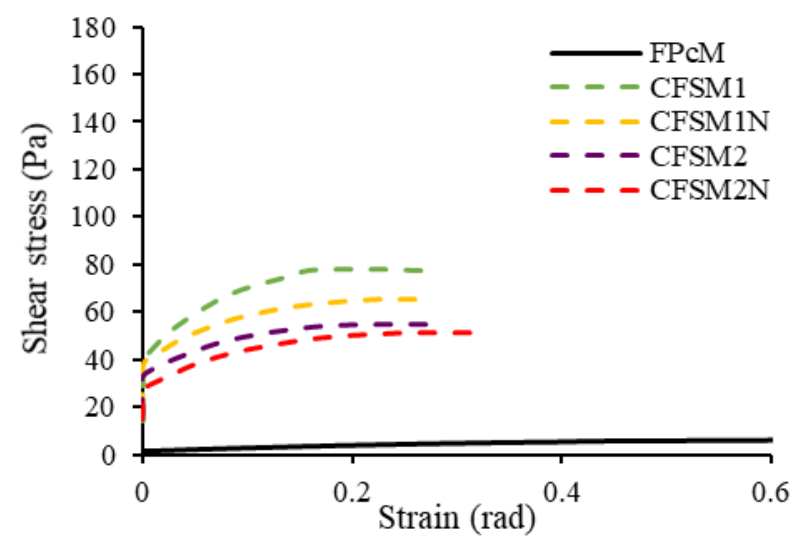

(b)

Figure 7. Shear stress-strain relationship: (a) binary mortars; (b) ternary mortars.

The ternary mortars exhibited lower yield stress varying from 51.2 to $77.4 \mathrm{~Pa}$ and correspondingly lower shear modulus (Table 4) than their binary counterparts. The presence of fly ash class F particles with a characteristic round shape in the mix composition enables quicker shear deformation of the material at lower stress values by inducing a ball-bearing-like effect (causing lower inter-particle friction) in the system. Additionally, high fly ash class $\mathrm{F}$ content of $55 \%$ by mass in the control mix led to lower yield stress for the same reasons mentioned above. Similar observations were reported in a previous study on fly ash-metakaolin-based two-part geopolymer grout, where an increase in the fly ash content decreased plastic viscosity and yield stress. This was attributed to the dense particle distribution and, thus, higher packing density of fly ash. Therefore, the substitution of metakaolin with fly ash improved the packing density and, eventually, enhanced the workability [37].

A decrease in yield stress was noted with the increased slump flow spread for the mortar mixes as per the equation (Slump flow $=-1.6796 \times$ yield stress +397.02 ) presented in Figure 8, indicating a linear correlation with a coefficient of 0.70. Similar behavior was reported in a previous study on Portland cement-based mortar, where the slump flow was influenced by the yield stress determined using theoretical simulations based on the Bingham model [22].

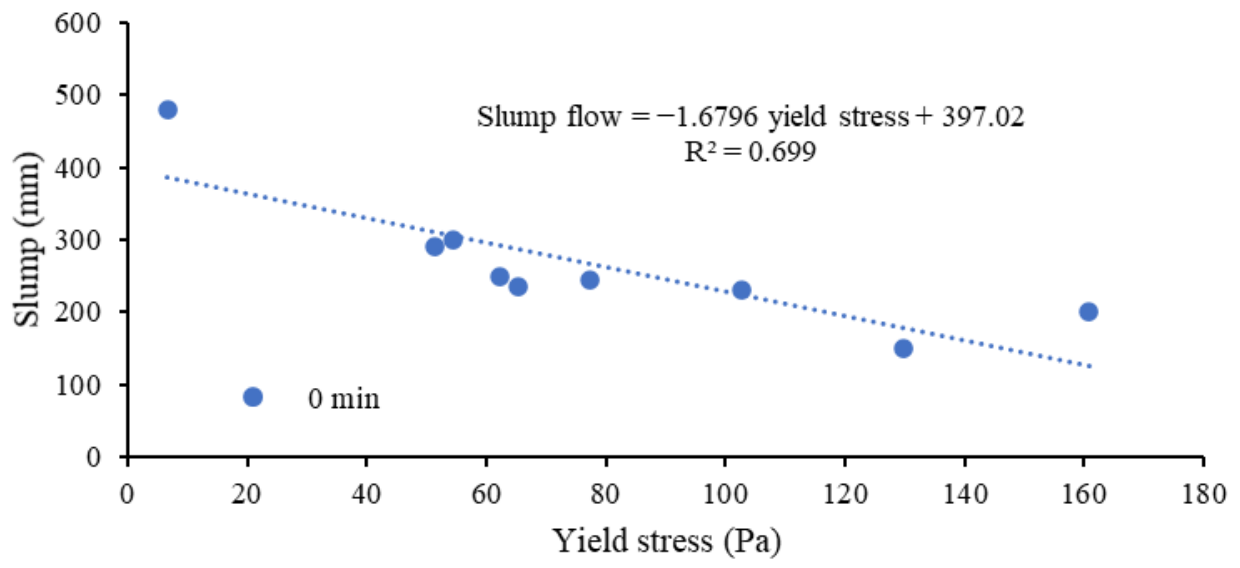

Figure 8. Yield stress versus slump flow.

\subsection{Microstructural Analysis}

The morphology and microstructural characteristics of the mortar specimens were studied under a scanning electron microscope (SEM) at 28 days. The reaction prod- 
ucts/elemental compositions determined using EDS analysis are discussed to relate their influence on fresh state and rheological properties.

The morphology of the binary (CS) mortars appears to be denser with a smaller number of un-hydrated/partially hydrated fly ash particles than their ternary (CFS) counterparts, as shown in Figure 9a,b. The fly ash particles are seen to be embedded in the matrix of ternary CFSM2 mortar, as indicated in Figure 9b. This can be attributed to the relatively lower reactivity of fly ash class $\mathrm{F}$ particles in CFSM2. The control mortar $\left(\mathrm{FP}_{\mathrm{C}} \mathrm{M}\right)$ exhibited the highest compressive strength of $43.5 \mathrm{MPa}$ (Table 3), and its matrix appeared to be the most compact among all the mortar specimens, with some of the FA-F particles acting as inert material filling up the void spaces, as noted in Figure 9c.

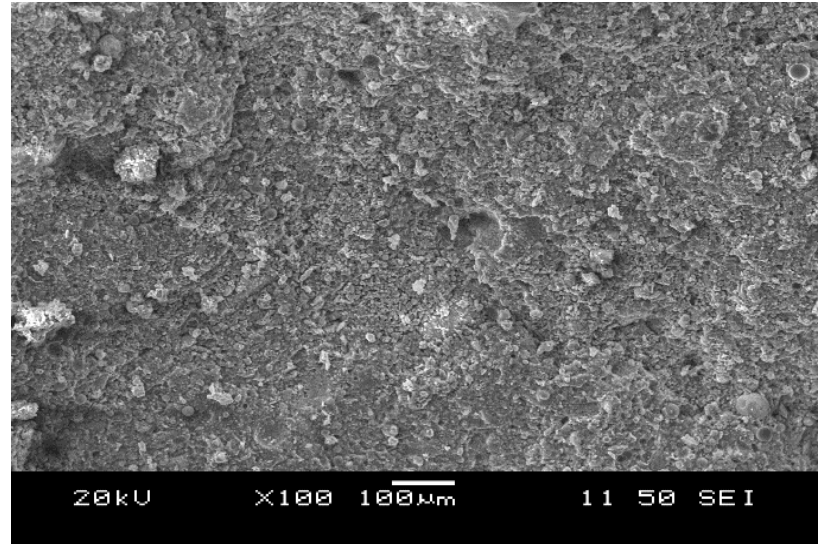

(a)

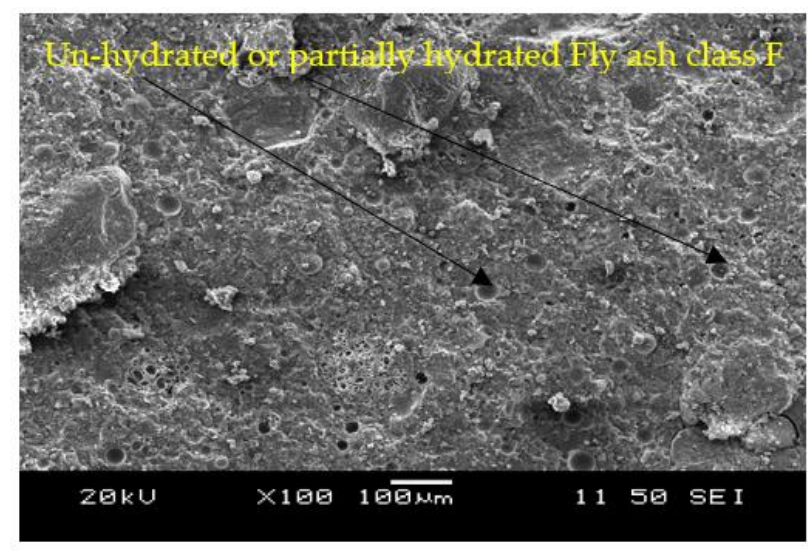

(b)

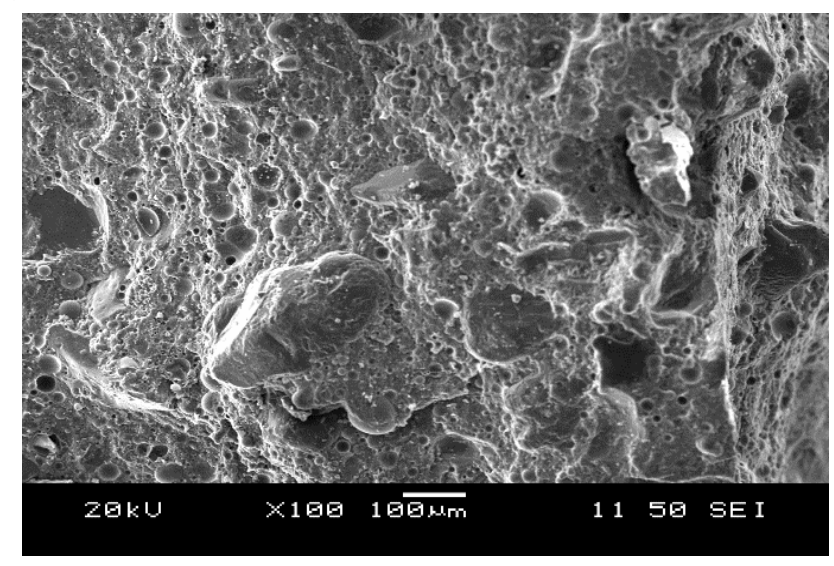

(c)

Figure 9. Morphology of the mortars at 28 days: (a) CSM2; (b) CFSM2; (c) FP $\mathrm{C}$.

The dominant reaction product for binary CSM2 mortar with reagent two consisted of C-A-S-H as evidenced by the presence of higher percentages of elements $(\mathrm{Ca}=17.9 \%$, $\mathrm{Si}=7.7 \%, \mathrm{Al}=4.1 \%$ and $\mathrm{O}=48.8 \%$ ) in the EDS analysis presented in Figure 10a. Additionally, the high calcium content in reagent two $\left(\mathrm{Ca}(\mathrm{OH})_{2}: \mathrm{Na}_{2} \mathrm{SO}_{4}=2.5: 1\right)$ led to the formation of Portlandite $\left(\mathrm{Ca}(\mathrm{OH})_{2}\right)$, which facilitated the synthesis of additional C-S-H gel. The formation of these gels (C-A-S-H/C-S-H) was also identified in fly ash/slag-based binders from previous research studies [38]. 

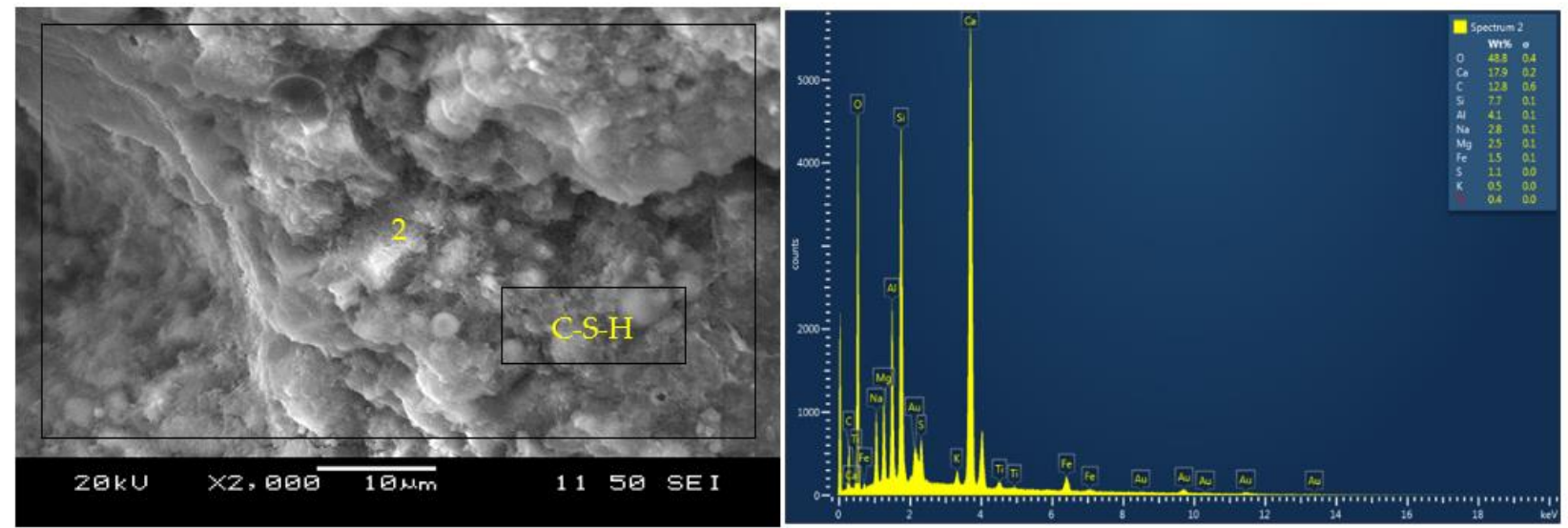

(a)
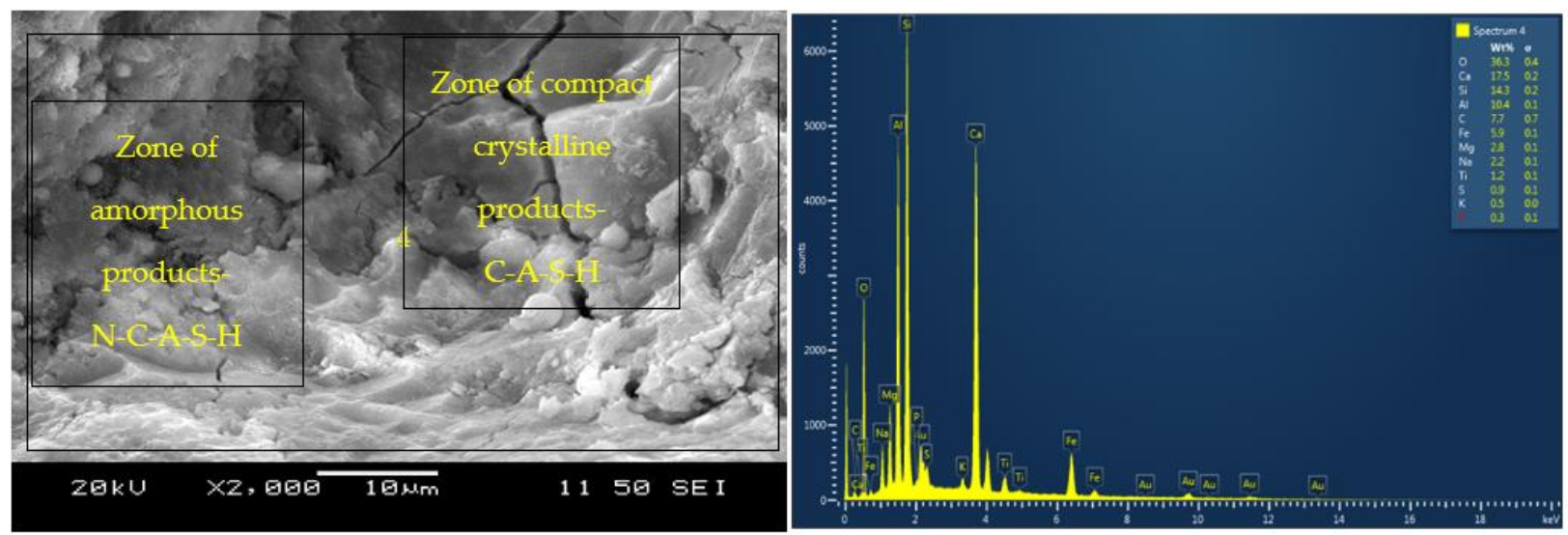

(b)
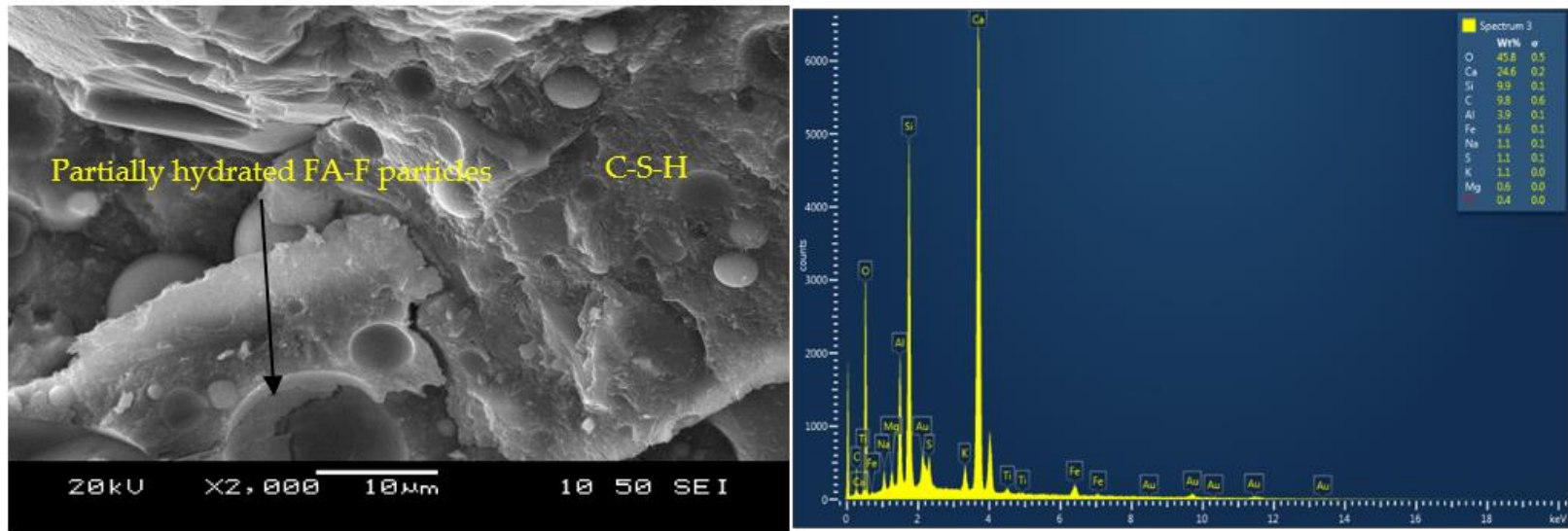

(c)

Figure 10. (a): SEM micrographs and EDS analysis of the binary mortar CSM2; (b): SEM micrographs and EDS analysis of the mortar CFSM2; (c): SEM micrographs and EDS analysis of the mortar $\mathrm{FP}_{\mathrm{C}} \mathrm{M}$.

A mix of amorphous and crystalline products can be observed from the SEM micrograph of ternary mortar CFSM2 with reagent two presented in Figure 10b. The main reaction product consisted of C-A-S-H gel as determined from major elements $(\mathrm{Ca}=17.5 \%$, $\mathrm{Si}=14.3 \%, \mathrm{Al}=10.4 \%, \mathrm{Na}=2.2 \%$ and $\mathrm{O}=36.3 \%$ ) in the EDS analysis. The higher calcium content in the CFSM2 composition facilitated silicate and aluminum ions' dissolution from fly ash. This enhanced dissolution of ions led to an improved alkali activation with addi- 
tional binding phases (C-S-H and N-C-A-S-H/N-A-S-H) responsible for higher strengths (Table 3) than their ternary counterpart with reagent one.

The formation of only crystalline C-A-S-H/C-S-H in binary (CS) mixes led to higher 28-day compressive strength (Table 3) than their ternary (CFS) counterparts, where a blend of crystalline (C-A-S-H) and amorphous (N-C-A-S-H/N-A-S-H) reaction products are formed with comparatively more un-hydrated or partially hydrated fly ash grains (Figure 10a,b). The production of C-A-S-H and C-S-H with shorter Si-Al linkages in both binary/ternary mixes with reagent two (Figure 10a,b) produced lower viscosity and yield stress with a higher slump flow (as confirmed from the fresh state and rheology test results presented earlier) compared to their reagent one counterparts, where the formation of $\mathrm{N}-\mathrm{C}-\mathrm{A}-\mathrm{S}-\mathrm{H}$ and N-A-S-H gels with comparatively longer polymeric chains in addition to C-A-S-H were found to be dominant as confirmed from authors' previous research [23].

The partially hydrated fly ash class F (FA-F) particles observed as embedded in the control mortar matrix $\left(\mathrm{FP}_{\mathrm{C}} \mathrm{M}\right)$ shown in Figure 10c facilitated the densification of the matrix by filling up the void spaces. The dominant hydration product, crystalline C-S-H gel, determined from the ruling elements $(\mathrm{Ca}=24.6 \%, \mathrm{Si}=9.9 \%, \mathrm{Al}=3.9 \%$ and $\mathrm{O}=45.8 \%)$ in SEM/EDS analysis, is responsible for its highest compressive strength amongst all the mortars. The hydrated FA-F improved the workability of the mixes, and the presence of shorter linkages in C-S-H gels in comparison to the alkali-activated gels (N-C-A-S-H/NA-S-H and C-A-S-H) resulted in the lowest plastic viscosity, lowest yield stress, highest slump flow spread and longest setting times among all the mortar mixes (as indicated in Table 4). On the other hand, the cement-free binary and ternary alkali-activated mortars exhibited the formation of a blend of crystalline (C-A-S-H/C-S-H) and amorphous (N-C-A$\mathrm{S}-\mathrm{H} / \mathrm{N}-\mathrm{A}-\mathrm{S}-\mathrm{H}$ ) products (Figure 10a,b), showing comparable fresh state, rheological and strength characteristics to that of the control mortar.

\section{Conclusions}

The characteristics of one-part alkali-activated mortars (AAMs) developed from binary (fly ash-C 'FA-C or C' + ground granulated blast furnace slag 'GGBFS or 'S') and ternary (FA$\mathrm{C}+$ fly ash-F 'FA-F or F' + GGBFS) combinations of supplementary cementitious materials (SCMs) with two types of powder-based reagents (calcium hydroxide + sodium metasilicate and calcium hydroxide + sodium sulfate) incorporating silica sand is described. The conclusions drawn from fresh state, rheological, hardened and microstructural properties of the developed eight binary (combinations of $C$ and $S$ ) and ternary (combinations of $C, F$ and S) AAMs compared to a control high volume fly ash-based cement counterpart are as follows:

- The AAM mortars incorporating reagent one $\left(\mathrm{Ca}(\mathrm{OH})_{2}: \mathrm{Na}_{2} \mathrm{SiO}_{3}=1: 2.5\right)$ obtained higher yield stresses than those with reagent two $\left(\mathrm{Ca}(\mathrm{OH})_{2}: \mathrm{Na}_{2} \mathrm{SO}_{4}=2.5: 1\right)$ owing to the relatively more significant formation of colloidal complexes (Si-O-H-Na) and $\mathrm{Si}-\mathrm{Al}$ binding phases. FA-F in ternary (CFS) mixes led to lower yield stress ranging from 51.2 to $77.4 \mathrm{~Pa}$ than their binary (CS) counterparts (62.2 to $160.8 \mathrm{~Pa}$ ). The shear modulus and yield stress were observed to decrease with the increase in the slump flow spread of the mortar mixes.

- The slump flow gradually reduced, and the plastic viscosity increased with time from 0 to $60 \mathrm{~min}$ after mixing. Lower slump flow/relative slump reductions were noted for mortars with reagent two (250 to $180 \mathrm{~mm}) /(5.2$ to 2.2$)$ than their counterparts with reagent one ( 245 to $105 \mathrm{~mm}) /(5.0$ to 0.1$)$ after $30 \mathrm{~min}$ of mixing. This lower decrease in slump flow spread of mixes with reagent two can be attributed to their higher liquid to solid ratios and the predominant formation of cementitious reaction products having shorter chains than the $\mathrm{Si}-\mathrm{Al}$ linkages in alkali-activation products formed in mixes with reagent one.

- There was no change in the slump flow of cement-based control mortar $\left(\mathrm{FP}_{\mathrm{C}} \mathrm{M}\right)$ with time (0 to 60 min after mixing). The high volume (55\%) fly ash class $F$ with characteristic round shape particles enhanced the workability, and the formation of 
shorter C-S-H linkages led to the lowest viscosity, lowest yield stress and highest compressive strength of the control mortar.

- All the AAM mixes showed decreased viscosity with an increase in shear rate up to 3.5 RPM depicting pseudoplastic behavior. The mixes with reagent two exhibited slightly lower or similar initial and final viscosities at 0.5 RPM. These binary and ternary mix compositions with reagent two (CSM2, CSM2N, CFSM2 and CFSM2N) also obtained lower viscosities/yield stresses and a higher slump flow spread than their counterparts with reagent one. This rheological behavior of reagent two mixes can be attributed to the dominant formation of cementitious gels (C-A-S-H and C-S-H) with shorter chains or linkages than the polymeric chains associated with geopolymeric products (N-A-S-H and N-C-A-S-H) formed in mixes with reagent one.

- The formation of both amorphous and crystalline phases in AAMs is evident from the SEM/EDS analysis. Portlandite formation in the mortars with reagent two is responsible for synthesizing additional binding phases resulting in higher compressive strengths than their counterparts with reagent one. The formation of C-A-S-H/C-S$\mathrm{H}$ and C-A-S-H/N-C-A-S-H as the primary binding phases for binary and ternary mortars is characterized from the SEM/EDS analysis.

- The shorter linkages/chains present in the cementitious (C-A-S-H and C-S-H) binding phases and higher liquid to solid (L/S) ratios of mixes with reagent two resulted in a higher flow spread/relative slump, lower plastic viscosities and yield stresses compared to mixes with reagent one with a more significant formation of geopolymeric (N-C-A-S-H and N-A-S-H) products. However, the AAM mixes with reagent one exhibited lower setting times than their counterparts with reagent two due to the high alkalinity of sodium metasilicate, leading to a comparatively higher degree of alkali-activation with a quicker formation of reaction products.

- The findings of this research bolster the feasibility of producing commercially viable cement-free one-part ambient cured AAMs incorporating binary or ternary combinations of SCMs, powder form reagents in lesser quantities and fine aggregates with fresh and hardened properties comparable to their heat-cured two-part solution-based counterparts and control cement-based mortars.

Author Contributions: Conceptualization, D.S. and K.M.A.H.; methodology, D.S. and K.M.A.H.; formal analysis, D.S. and K.M.A.H.; investigation, D.S. and K.M.A.H.; resources, K.M.A.H.; writingoriginal draft preparation, D.S. and K.M.A.H.; writing-review and editing, D.S. and K.M.A.H.; supervision, K.M.A.H.; project administration, K.M.A.H.; funding acquisition, K.M.A.H. All authors have read and agreed to the published version of the manuscript.

Funding: This research was funded by Natural Science and Engineering Research Council (NSERC), Canada, grant number RGPIN 5613-2019.

Institutional Review Board Statement: Not applicable.

Informed Consent Statement: Not applicable.

Acknowledgments: The authors gratefully acknowledge the supports provided by the technical staffs of Concrete and Structure laboratories of the Department of Civil Engineering, Ryerson University, Toronto, Canada.

Conflicts of Interest: The authors declare no conflict of interest.

\section{References}

1. Farasat, S.; Shah, A.; Chen, B.; Yousefi, S.; Haque, M.A.; Riaz, M. Improvement of early strength of fly ash-slag based one-part alkali activated mortar. Constr. Build. Mater. 2020, 246, 1-10.

2. Hossain, K.M.A. Blended cement using volcanic ash and pumice. Cem. Concr. Res. 2003, 33, 1601-1605. [CrossRef]

3. Hossain, K.M.A. Performance of Volcanic Ash Based Precast and In Situ Blended Cement Concretes in Marine Environment. J. Mater. Civ. Eng. 2005, 17, 694-702. [CrossRef]

4. Shah, F.A.; Chen, B.; Oderji, S.Y.; Haque, M.A.; Ahmad, M.R. Comparative study on the effect of fiber type and content on the performance of one-part alkali-activated mortar. Constr. Build. Mater. 2020, 243, 1-9. [CrossRef] 
5. Alzaza, A.; Ohenoja, K.; Illikainen, M. One-part alkali-activated blast furnace slag for sustainable construction at subzero temperatures. Constr. Build. Mater. 2021, 276, 1-11. [CrossRef]

6. Abdollahnejad, Z.; Mastali, M.; Falah, M.; Shaad, K.M.; Luukkonen, T.; Illikainen, M. Durability of the Reinforced One-Part Alkali-Activated Slag Mortars with Different Fibers. Waste Biomass Valorization 2021, 12, 487-501. [CrossRef]

7. Alrefaei, Y.; Wang, Y.-S.; Dai, J.-G. The effectiveness of different superplasticizers in ambient cured one-part alkali activated pastes. Cem. Concr. Compos. 2019, 97, 166-174. [CrossRef]

8. Luukkonen, T.; Sreenivasan, H.; Abdollahnejad, Z.; Yliniemi, J.; Kantola, A.; Telkki, V.V.; Kinnunen, P.; Illikainen, M. Influence of sodium silicate powder silica modulus for mechanical and chemical properties of dry-mix alkali-activated slag mortar. Constr. Build. Mater. 2020, 233, 1-10. [CrossRef]

9. Alonso, M.M.; Gismera, S.; Blanco, M.T.; Lanzon, M.; Puertas, F. Alkali-activated mortars: Workability and rheological behaviour. Constr. Build. Mater. 2017, 145, 576-587. [CrossRef]

10. Kwan, A.K.H.; Li, Y. Effects of fly ash microsphere on rheology, adhesiveness and strength of mortar. Constr. Build. Mater. 2013, 42, 137-145. [CrossRef]

11. Kwasny, J.; Sonebi, M.; Plasse, J.; Amziane, S. Influence of rheology on the quality of surface finish of cement-based mortars. Constr. Build. Mater. 2015, 89, 102-109. [CrossRef]

12. Hafid, H.; Ovarlez, G.; Toussaint, F.; Jezequel, P.H.; Roussel, N. Effect of particle morphological parameters on sand grains packing properties and rheology of model mortars. Cem. Concr. Res. J. 2016, 80, 44-51. [CrossRef]

13. Celikten, S.; Sarıdemir, M.; Deneme, I.O. Mechanical and microstructural properties of alkali-activated slag and slag + fly ash mortars exposed to high temperature. Constr. Build. Mater. 2019, 217, 50-61. [CrossRef]

14. Xie, T.; Ozbakkaloglu, T. Behavior of low-calcium fly and bottom ash-based geopolymer concrete cured at ambient temperature. Ceram. Int. 2015, 41, 5945-5958. [CrossRef]

15. Palacios, M.; Banfill, P.F.G.; Puertas, F. Rheology and setting of alkali-activated slag pastes and mortars: Effect of organic admixture. ACI Mater. J. 2008, 105, 140-148.

16. Yang, K.H.; Song, J.K.; Ashour, A.F.; Lee, E.T. Properties of cementless mortars activated by sodium silicate. Constr. Build. Mater. 2008, 22, 1981-1989. [CrossRef]

17. Zhu, Y.; Yang, Y.; Yao, Y. Use of slag to improve mechanical properties of engineered cementitious composites (ECCs) with high volumes of fly ash. Constr. Build. Mater. 2012, 36, 1076-1081. [CrossRef]

18. Puertas, F.; Varga, C.; Alonso, M.M. Rheology of alkali-activated slag pastes. Effect of the nature and concentration of the activating solution. Cem. Concr. Compos. 2014, 53, 279-288. [CrossRef]

19. Criado, M.; Palomo, A.; Fernández-Jiménez, A.; Banfill, P.F.G. Alkali activated fly ash: Effect of admixtures on paste rheology. Rheol. Acta 2009, 48, 447-455. [CrossRef]

20. Banfill, P.F.G. Simultaneous rheological and kinetic measurements on cement pastes. Cem. Concr. Res. 1991, $21,1148-1154$. [CrossRef]

21. Lachemi, M.; Hossain, K.M.A.; Lambros, V.; Nkinamubanzi, P.-C.; Bouzoubaâ, N. Performance of new viscosity modifying admixtures in enhancing the rheological properties of cement paste. Cem. Concr. Res. 2004, 34, 185-193. [CrossRef]

22. Wallevik, J.E. Relationship between the Bingham parameters and slump. Cem. Concr. Res. 2006, 36, 1214-1221. [CrossRef]

23. Sood, D.; Hossain, K.M.A. Optimizing Precursors and Reagents for the Development of Alkali-Activated Binders in Ambient Curing Conditions. J. Compos. Sci. 2021, 5, 59. [CrossRef]

24. Sood, D.; Hossain, K.M.A.; Manzur, T.; Hasan, M.J. Developing Geopolymer Pastes Using Dry Mixing Technique. In Proceedings of the 7th International Conference on Engineering Mechanics and Materials, Laval, QC, Canada, 12-15 June 2019; pp. 1-8.

25. Sherir, M.A.A.; Hossain, K.M.A.; Lachemi, M. Self-healing and expansion characteristics of cementitious composites with high volume fly ash and MgO-type expansive agent. Constr. Build. Mater. 2016, 127, 80-92. [CrossRef]

26. Sherir, M.A.A.; Hossain, K.M.A.; Lachemi, M. Permeation and Transport Properties of Self-Healed Cementitious Composite Produced with MgO Expansive Agent. J. Mater. Civ. Eng. 2018, 30, 1-12. [CrossRef]

27. Nematollahi, B.; Sanjayan, J.; Shaikh, F.U.A. Matrix design of strain hardening fiber reinforced engineered geopolymer composite. Compos. Part B Eng. 2016, 89, 253-265. [CrossRef]

28. Nematollahi, B.; Sanjayan, J. Effect of different superplasticizers and activator combinations on workability and strength of fly ash based geopolymer. Mater. Des. 2014, 57, 667-672. [CrossRef]

29. ASTM International. ASTM C1437, Standard Test Method for Flow of Hydraulic Cement Mortar; ASTM International: West Conshohocken, PA, USA, 2015.

30. ASTM International. ASTM C191-18a, Standard Test Methods for Time of Setting of Hydraulic Cement by Vicat Needle; ASTM International: West Conshohocken, PA, USA, 2018.

31. ASTM International. ASTM C109/C109 M. Standard test Method for Compressive Strength of Hydraulic Cement Mortars (Using 2-in. or [50-mm] Cube Specimens); ASTM International: West Conshohocken, PA, USA, 2016.

32. American Concrete Institute. ACI Committee 318. Building Code Requirements for Structural Concrete and Commentary; ACI 318-19; American Concrete Institute: Farmington Hills, MI, USA, 2019.

33. Palacios, M.; Alonso, M.M.; Varga, C.; Puertas, F. Influence of the alkaline solution and temperature on the rheology and reactivity of alkali-activated fly ash pastes. Cem. Concr. Compos. 2019, 95, 277-284. [CrossRef] 
34. Panda, B.; Unluer, C.; Tan, M.J. Extrusion and rheology characterization of geopolymer nanocomposites used in 3D printing. Compos. Part B 2019, 176, 1-9. [CrossRef]

35. Vance, K.; Dakhane, A.; Sant, G.; Neithalath, N. Observations on the rheological response of alkali activated fly ash suspensions: The role of activator type and concentration. Rheol Acta 2014, 53, 843-855. [CrossRef]

36. Tognonvi, M.T.; Massiot, D.; Lecomte, A.; Rossignol, S.; Bonnet, J.-P. Identification of solvated species present in concentrated and dilute sodium silicate solutions by combined 29 Si NMR and SAXS studies. J. Colloid Interface Sci. 2010, 352, 309-315. [CrossRef] [PubMed]

37. Aboulayt, A.; Jaafri, R.; Samouh, H.; El Idrissi, A.C.; Roziere, E.; Moussa, R.; Loukili, A. Stability of a new geopolymer grout: Rheological and mechanical performances of metakaolin-fly ash binary mixtures. Constr. Build. Mater. 2018, 181, 420-436. [CrossRef]

38. Pan, Z.; Tao, Z.; Cao, Y.F.; Wuhrer, R.; Murphy, T. Compressive strength and microstructure of alkali-activated fly ash/slag binders at high temperature. Cem. Concr. Compos. 2018, 86, 9-18. [CrossRef] 